\title{
Advances on Coastal and Estuarine Circulations Around the Changjiang Estuary in the Recent Decades (2000-2020)
}

\begin{abstract}
Zhiqiang Liu ${ }^{1,2 *}$, Jianping Gan ${ }^{3,4}$, Hui Wu ${ }^{5}$, Jianyu $\mathrm{Hu}^{6}$, Zhongya $\mathrm{Cai}^{7}$ and Yongfei Deng ${ }^{1}$
${ }^{1}$ Department of Ocean Science and Engineering, Southern University of Science and Technology, Shenzhen, China, ${ }^{2}$ Southern Marine Science and Engineering Guangdong Laboratory, Guangzhou, China, ${ }^{3}$ Department of Ocean Science, Hong Kong University of Science and Technology, Hong Kong, China, ${ }^{4}$ Department of Mathematics, Hong Kong University of Science and Technology, Hong Kong, China, ${ }^{5}$ State Key Laboratory of Estuarine and Coastal Research, East China Normal University, Shanghai, China, ${ }^{6}$ State Key Laboratory of Marine Environmental Science, Xiamen University, Xiamen, China, ${ }^{7}$ State Key Laboratory of Internet of Things for Smart City, Department of Civil and Environmental Engineering, University of Macau, Macau, China
\end{abstract}

Advances on the circulation in the Changjiang Estuary and adjacent East China Sea (ECS) and Yellow Sea (YS) coastal waters in the recent decades (2000-2020) are synthesized in this review. The circulation over the complicated bathymetry in the region is locally driven by winds, tides, as well as riverine discharge, and is remotely influenced by shelf currents between the 50 and $100-\mathrm{m}$ isobaths through the cross-shelf exchanges. The interchange of the momentum and the freshwater pathway inside the Changjiang Estuary are jointly determined by tides and seasonally varying discharge and winds over the shelf. The buoyant waters are trapped inside the bulge that forms and expands over the shelf to the west of the 30-m isobath in the vicinity of Hangzhou Bay and the Changjiang Estuary. These buoyant waters are exported offshore by the shelf current, tidal mixing, and variations of wind patterns, forming the Changjiang River plume, which shows notable seasonality due to the reversal of both winds and shelf currents in the ECS and YS. Extensive spatial irregularities in the form of freshwater patches are present along its pathway to the Tsushima Strait in summer and to the Taiwan Strait in winter, respectively. Tides and the bathymetry irregularity have recently been found to play critical roles in determining the cross-shelf exchanges of water mass and momentum along the pathway of the ECS coastal current, and along this pathway, a year-round upslope intrusion of shelf waters appears in both summer and winter. Tides also play an important role in altering the expansion of the Changjiang River plume, cross-shelf extrusion of waters, and variation in the Yellow Sea Coastal Current over the shallow Subei Shoal.

Keywords: Changjiang (Yangtze river) estuary, coastal circulation, East China Sea, river plume, bulge

\section{INTRODUCTION}

The coastal waters in the East China Sea (ECS) and southern Yellow Sea (YS) are found over their respective shelves to the west of the $50-\mathrm{m}$ isobath, which extends northward from $\sim 25^{\circ} \mathrm{N}$ to $\sim 37^{\circ} \mathrm{N}$ (Figure 1A). These coastal waters are bordered by the southern coast of the Shandong and the coastlines of the Jiangsu, Shanghai, Zhejiang, and Fujian. In the southern ECS, the interlinked 
coastal waters mainly extend southwestward, running parallel to the Fujian and Zhejiang coasts to the south of the Changjiang Estuary. The complicated coastlines are composed by many islands, bays, and channels, such as those in the vicinity of the Zhoushan Islands and Changjiang Estuary. Coastal waters in the southern ECS are generally shallower than $50 \mathrm{~m}$, except in some deep channels with depths $>100 \mathrm{~m}$ among the Zhoushan Islands. The Hangzhou Bay and the Changjiang Estuary widen toward the east and the ECS. The bathymetry of the coastal waters in the southwestern YS is generally characterized by the Subei Shoal (a.k.a. the Yangtze Bank), which extends to the southeast and over which the nearshore waters are generally shallower than $10 \mathrm{~m}$. A northwestward incising submerged valley is surrounded by the $50-\mathrm{m}$ isobath in the northwestern ECS to the southwest of the Subei Shoal. The northwestward extending YS Trough characterizes the bathymetry of the southern YS.

The Changjiang River is the largest river in the East Asia and exports buoyant waters with an averaged discharge rate of $\sim 26,400 \mathrm{~m}^{3} / \mathrm{s}$ into the ECS and YS (Mei et al., 2015). The water depth in this long estuary is generally shallower than $20 \mathrm{~m}$, and riverine waters rush into the ECS shelf through its complicated passages and channels (Figure 1B). The Changjiang Estuary is divided into the North and South Branches by the Chongming Island. In the mid-estuary, the Changxing Island separates the South Branch into the North and South Channels. The anthropogenic underwater infrastructure and the navigation channel in the vicinity of Hengsha Island further divide the South Channel into the North and South Passages. This complicated bathymetry, which will be explored in the following sections, greatly alters the characteristics of the circulation and freshwater as well as the interaction between the estuarine circulation and the coastal circulation at the mouth of the Changjiang Estuary. Coastal circulations over the complicated nearshore bathymetry to the west of the 50-m isobath in the ECS and southern YS are jointly forced by variable multiscale local forcing, including tides, winds, and river discharge. Coastal and estuarine circulations also interact with shelf circulations, for example, the Taiwan Warm Current (TWWC), Yellow Sea Warm Current (YSWC, in winter), and Yellow Sea Cold Water Mass (YSCM, in summer) as well as the Kuroshio in the Okinawa Trough and the Taiwan Strait Current (TSC).

The Kuroshio and the intrinsic characteristics of the ECS shelf current act as the major external factors that influence coastal and estuarine circulation. The annually average volume transport of the Kuroshio is $\sim 24.37 \mathrm{~Sv}$ in the central ECS (Liu et al., 2021), and a stronger/weaker Kuroshio is usually present in the warm/cold half of the year in the northern hemisphere (Yang et al., 2018). Observations based on the conservation of the total water volume over the shelf reveal that the integrated volume transport by the Kuroshio intrusion into the ECS is $\sim 1.3-$ $1.4 \mathrm{~Sv}$ (Isobe, 2008). The shelf currents, which originate from the southern ECS, interact with the circulation between the 100 and 200-m isobaths and flow into the Tsushima Strait, exiting into the southern Japan Sea further north (Gan et al., 2016; Lie and Cho, 2016; Li et al., 2016). The northward penetrating warm waters in the ECS are from the TSC and those that originated from the Kuroshio intrusion over the shelf to the northeast of Taiwan [synthesized by $\mathrm{Hu}$ and Wang (2016) and simulated by Yang et al. (2013), among others]. They form the northward flowing TWWC, which greatly modulates the shoreward intrusion of shelf waters toward the coastal seas off the Zhejiang and Fujian coasts in summer. This northward current has also been found to be largely regulated by the southwestward flowing Zhe-Min Coastal Current (ZMCC), which carries buoyant waters from the Changjiang River to the Taiwan Strait in winter. The TSC and the interactions between the TWWC and ZMCC are also greatly regulated by synoptic wind variability, which establishes downshelf propagating coastally trapped waves that alter the respective intensity of these currents (Li and Huang, 2019).

In the southern YS, a notable northward penetration of warm waters, indicative of YSWC, is observed in the Yellow Sea Trough in winter. Previous studies have recognized that the YSWC mainstream shifts westward toward the eastern flank of the shallower Subei Shoal (Lin and Yang, 2011; Lin et al., 2011), where tides have been suggested to play important roles in regulating the regional circulation. The circulation in summer is mainly governed by the monsoonal winds, tides, Changjiang River Plume and the YSCM, which resides from the YSWC in winter and is sealed in the lower layers of the Yellow Sea Trough in summer. The expansion of the Changjiang River Plume, whose underlying dynamics will be further explored in the following sections, shows notable spatial variations in its pathways in the ECS and southern YS.

We revisit recent understandings on estuarine circulation in the Changjiang River Estuary and coastal circulations in the ECS and southern YS, and pay more attention on the circulation dynamics than the recent comparative reviews, which focus more on the seasonal (Guan and Fang, 2006; Lie and Cho, 2016) and interannual (Matsuno, 2020) variabilities of the shelf waters and biogeochemical processes (Chen J. et al., 2020) to the further seaward of the studied area. The rest of this manuscript is arranged as follow. In Section Changjiang estuarine circulation, we synthesize the characteristics of the circulation in the Changjiang Estuary. The expansion of the Changjiang river plume is synthesized in Section Changjiang River plume. Section Coastal Currents in the ECS and southern YS summarizes recent advances on the coastal currents in the ECS and southern YS, and the impact of circulation dynamics on hypoxia off the Changjiang Estuary is synthesized in Section Impacts of Circulation on Hypoxia off the Changjiang Estuary. The summary and prospects are given in Section Summary and Prospects.

\section{CHANGJIANG ESTUARINE CIRCULATION}

The Changjiang River is the largest river in the East Asia and the fifth largest river worldwide in terms of riverine discharge. The maximum/minimum discharge rate of Changjiang River appears in summer/winter $\left(\sim 40,000 / \sim 13,000 \mathrm{~m}^{3} / \mathrm{s}\right)$ (Luan et al., 2016). The buoyant waters that flow through the complicated passages and channels of the Changjiang Estuary (Figure 1B) form the interactive estuarine circulation, and its underlying mechanisms have often been investigated in studies of the general flow pattern [e.g., Xue et al. (2009) and the references therein]. Majority of the 


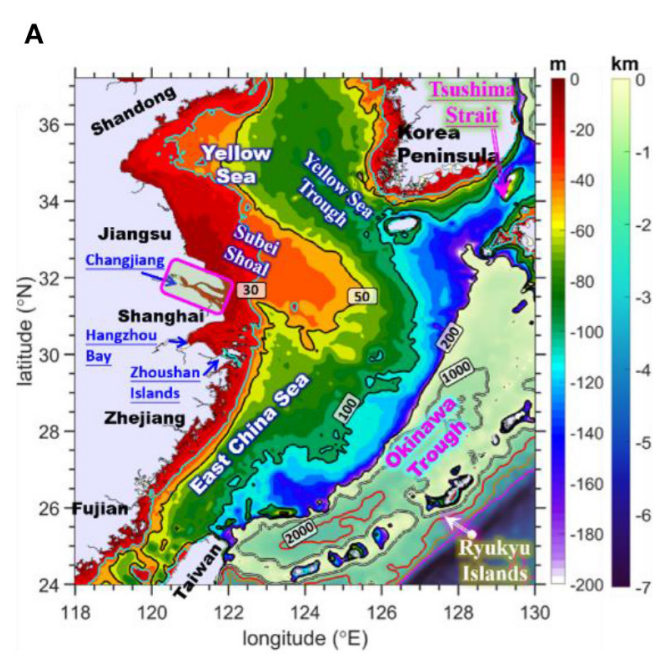

B

FIGURE 1 | (A) Water depth ( $\mathrm{m}$ ) of ECS and YS. The waters deeper and shallower than $200 \mathrm{~m}$ in this figure are illustrated by different colormaps. The 30, 50, 100, and $200 \mathrm{~m}$ isobaths over the shelf, and 1,000,2,000, 3,000, 4,000 $\mathrm{m}$ isobaths in the deeper oceans are also shown. The bathymetry is composed from the digitalized navigation map in the coastal areas and the ETOPO1 global relief model. (B) Water depth ( $\mathrm{m}$ ) in Changjiang Estuary with name of the branches, channels, passages, and islands (Zhu et al., 2019). The underwater jetty spur bordering the North Passage is shown in (B).

riverine runoff rushes into the ECS through the South Branch, which, in winter, counts for over 95\% of the discharges ( $\mathrm{Li}$ et al., 2010). The partitioning of buoyant waters toward the North Branch $(<5 \%)$ oscillates with flood and ebb tides and varies in the spring and neap tidal cycles. The main features of Changjiang estuarine circulation are an onshore intrusion of shelf waters and the extrusion of buoyant waters, which are also modulated by anthropogenic activities. It should be noted that although we, respectively, reviewed the characteristics of the intrusion of shelf waters and the extrusion of riverine waters, the exchange flow in the Changjiang Estuary is composition of these bidirectional circulations with the general circulation pattern is shown in the Figure 2, and the underlying dynamics are synthesized in the follow contents.

\section{Intrusion of Shelf Waters}

The Changjiang estuarine circulation is generally stronger in summer (Figure 2A) than that in winter (Figure 2B). In addition to the intrusion of the shelf waters from the lower layer at the mouth of the estuary (Figure 2C), there is a long-distance intrusion of saltwater from the North Branch to the South Branch (white arrows in North Branch and the black arrows in South Branch in Figure 2C). This intrusion, due to its notable threat on freshwater supply of the neighboring cities, is the focus of the previous studies in the recent decades and it is reported to occasionally inject saltwater into the mainstream freshwater of the South Branch (Xu et al., 2018). This intrusion is regulated by the intensity of upstream riverine runoff and the tidal range over the shelf neighboring the North Branch in the lower estuary (Wu et al., 2006), as well as winds over the shelf off the Changjiang Estuary (Zhang et al., 2017; Lyu and Zhu, 2018; Zhu et al., 2018a; Zhu et al., 2019). The respective responses of the estuarine circulation in those complicated branches and channels to those forces will be further synthesized in the following contents.

The intrusion of salt waters from the North Branch to the South Branch is greatly altered by the tidal and wind forcings. The non-linearity of the tidally induced momentum flux and bottom friction over the abrupt topography induce tidal rectification (Xue et al., 2009). The invasion of shelf waters through the North Branch then occurs when the intensity of the freshwater flow in this branch is weaker than that of the tidally rectified current. The influence of non-linear tidal rectification in modulating the exchanges among the channels and passages in the Changjiang Estuary network was also described in detail by Alebregtse and de Swart (2016), which further emphasized the attenuation of the semi-diurnal tide by extensive riverine discharge in summer. The associated non-linear river-tide interactions diminish the semidiurnal variation of the surface-elevation amplitude and thus have minimal effects on the tidal velocity amplitude and phase of tidal waves. The numerical experiments in Qiu et al. (2012) showed that the water exchanges between the North Branch and South Branch are much stronger during spring tides than during neap tides. The intrusion of shelf waters from the North Branch toward the South Branch also shows notable seasonality. In winter, the tidally rectified current is intensified to strengthen the intrusion of shelf waters from the North Branch toward the South Branch, when the seaward surface elevation gradient (i.e., barotropic pressure gradient) is reduced by northerly winds (Xue et al., 2009). The estuary-ward Ekman transport by the northerly winds strengthens the intrusion of saltwater toward the South Branch (Li et al., 2010, 2012), and this intrusion is greatly intensified since 1999, possibly due to the more frequent 
A

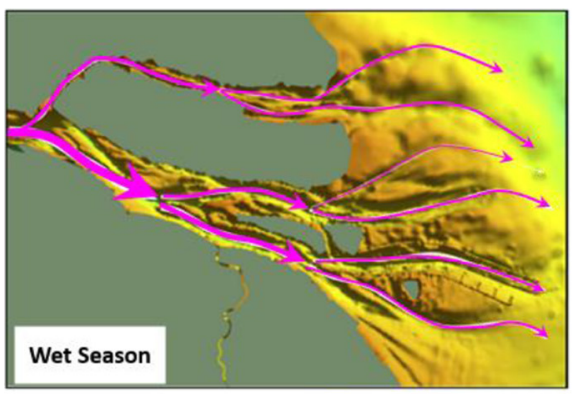

B

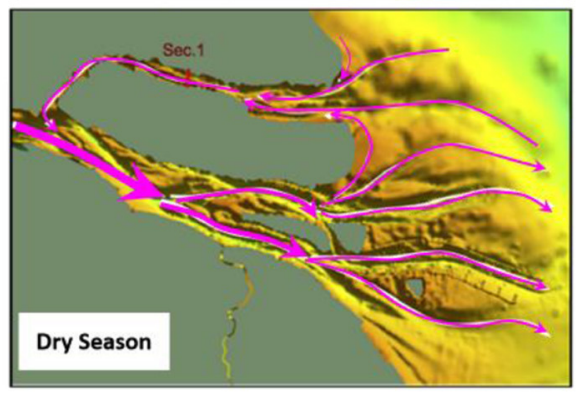

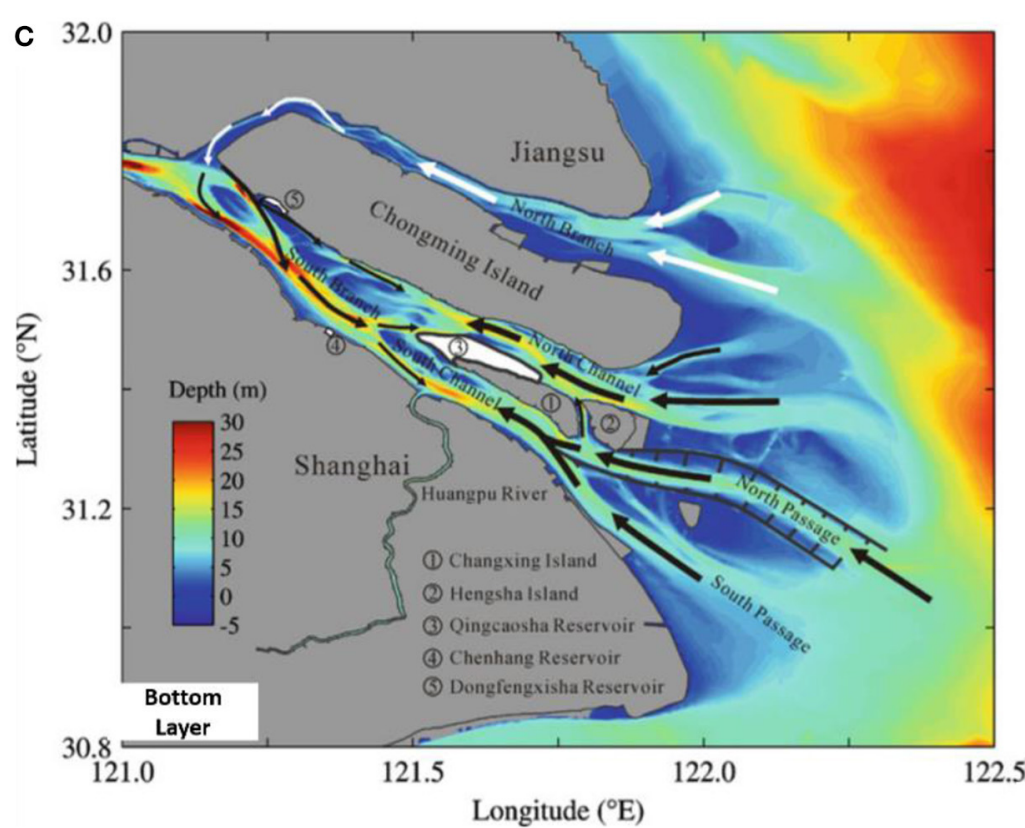

FIGURE 2 | Schematics of the subtidal flow patterns (Xue et al., 2009) during (A) wet and (B) dry seasons, and (C) pathways for saltwater intrusion (arrows) (Zhu et al., 2015), with the white and black arrows in (C) denoting pathway of the onshore invading shelf waters.

outbreaks of northerly and northeasterly wind event (Zhang et al., 2019a). Water exchange between the South Channel and North Channel is greatly affected by the variation in wind direction (Li et al., 2012). When the northeasterly wind prevails, saltwater intrusions in the North Channel have been found to be weaker than those imposed by the northerly winds. Li L. et al. (2014) found that the shelf water intrusions in the North Channel are amplified due to the deepening topography mid-channel and to the east of Chongming Island.

In the further downstream, circulations in the South Passage and North Passage are also greatly influenced by tides and winds. The numerical simulations by Wu and Zhu (2010) and Wu et al. (2010) suggested that tidally induced subtidal circulation plays an important role, and Stokes transport due to the propagation of tidal waves has been found to amplify the onshore invasion of shelf waters in the South Passage. This process makes the South Passage the most saline outlet besides the North Branch. The circulation in the North Channel and North Passage is primarily dominated by the extensive seaward export of riverine buoyant waters. Passive tracers deployed in a simulation have further revealed a significant intrusion of saltwater in the South Passage toward the North Passage, and this intrusion has been found to be diminished by northerly winds.

\section{Extrusion of Riverine Waters}

The riverine waters mainly extrude out of the Changjiang Estuary through the South Branch. The transport time required for the buoyant waters to travel from the river entrance (XuLiuJing in Figure 1B) to the estuary exit $\left(\sim 122.5^{\circ} \mathrm{E}\right)$ is approximately 23 and 35 days for high and low discharge conditions, respectively (Wang et al., 2010). The time required for the buoyant waters to exit the estuary increases from the North Channel to the South Channel and from the North Passage to the South Passage due to the diversion of freshwater discharge and the increase in bottom friction. The gravitational exchange flow at the exit of the estuary accelerates the seaward export of the buoyant waters from the river entrance further downstream.

This transport time experiences notable seasonality and spring-neap variation (Wang Y. et al., 2015). It is greater in winter compared to that in summer, and the seaward export of freshwater is stronger during the neap-tide period than during the spring-tide period. Similarly, field observations have shown that the residual current in the North Passage is stronger in summer than that in winter, and it is more influential during spring tides than during neap tides ( $\mathrm{Pu}$ et al., 2015). Tidal stirring, longitudinal and lateral depth-mean straining act as the principal mechanism determining the contrasting mixing intensity observed during spring and neap tides (Pu et al., 2016). The tidal effect is more important in winter, when the discharge rate is greatly reduced, compared to that in summer (Zhang et al., 2017). Tidal waves invade further upstream toward the South Branch in winter (Zhang et al., 2018a). Surface elevation at the upstream of the South Branch is higher in summer than that in winter, while variations of surface elevation is minimal at the estuary exit. In the down-estuary section, a higher barotropic pressure gradient is thereafter established in summer. The lateral circulation in the cross-branch direction is generated by the 
barotropic pressure gradient to enhance the intrusion of shelf waters in the North Channel (Zhu et al., 2018b).

\section{Anthropogenic Impacts}

Anthropogenic impacts on the Changjiang estuarine circulation are represented by the Three Gorges Dam in the further upstream of the river (not shown), the progressive narrowing of the North Branch and the underwater infrastructure in the North Passage (Figure 2B). The impoundment of Three Gorges Dam was considered to greatly alter the streamflow (Zhang et al., 2019b; Wang et al., 2020; Yu et al., 2020a) and nutrient discharges of Changjiang river and thereby have a great potential in altering the hydrographic properties (Yan et al., 2008), sediments (Dai et al., 2016) and biogeochemical processes (Chai et al., 2009) in the estuary and thereafter the coastal seas. The increased discharge rate in the dry season, due to impoundment of Three Gorges Dam could be favorable for ensuring the freshwater supplement (Cai et al., 2019) and has potentials to suppress the injection of saltwater from the North Branch to the South Branch. The incremental anthropogenic impacts, such as the narrowing and shallowing of the North Branch, also progressively reduced the saltwater intrusions from the North Branch to the South Branch, and the topographic changes in the North Channel from 2007 to 2017 strengthened/weakened the intrusion of shelf waters during spring/neap tides (Chen et al., 2019). However, the role of Three Gorges Dam in changing the estuarine and coastal circulations is considered to be secondary referring to the underwater infrastructure in the North Passage (Wu et al., 2018c). The large-scale underwater construction (Figure 1B) in the vicinity of Hengsha Island greatly strengthens the tidal current (Zhang et al., 2018a), direction of rotation and vertical structure of the tidal ellipse ( $\mathrm{Pu}$ et al., 2017) and thereby stability of the inside waters (Wan and Zhao, 2017), thus altering the stratification in the North Passage (Ma et al., 2011; Wan et al., 2014; Chen et al., 2020b). This underwater construction diminishes the freshwater partition in the South Channel while amplifies the onshore intrusion of saltwater in the South and North Passages, and alleviates the invasion of shelf waters in the North Channel by reducing/increasing the partition of riverine waters in the South/North Channel (Zhu et al., 2018a; Zhu et al., 2019). From the North to the South Channel, an anticlockwise circulation anomaly is thereby established (Li et al., 2020). The built underwater jetty spur (Figure 1B) has greatly increased the transport time by $50 \%$ (Wang et al., 2010). This underwater infrastructure has also been observed to strengthen the southward motion of the Changjiang River plume over the shelf by eliminating the lateral circulation at the estuary exit, where the northeastward extension of the buoyant plume begins (Wu et al., 2018c).

\section{CHANGJIANG RIVER PLUME}

The Changjiang River plume is formed by the massive amount of freshwater extruding through the Changjiang Estuary and plays a critical role in determining the regional circulation in the coastal seas. For example, the recent synthesis of previous observations and numerical simulations showed the seasonality of the coastal circulation over the shelf to the west of the $50-\mathrm{m}$ isobath (Wu and $\mathrm{Wu}, 2018$ ), and a year-round persisting bottom-trapped plume off the Zhejiang and Fujian coasts is proposed (Zhang et al., 2020). This bottom-trapped plume is critically sustained by extensive tidal mixing, and it imposes an unexpected counterwind southwestward coastal current off Zhejiang in the summers of 2006 and 2009 (Li et al., 2014b).

The Changjiang River Plume also interacts with the TWWC in the central ECS shelf, the TSWC in the Tsushima Strait (Isobe et al., 2002), and TSC in the Taiwan Strait (Lie and Cho, 2016), and shows notable seasonality and remarkable spatial variation, which is characterized by distinct flow patterns over the shelf of the coastal sea off the Changjiang Estuary. These freshwaters can also greatly impact the connectivity between the Japan Sea and the northern ECS by altering the baroclinicity of the water in the Tsushima Strait in summer (Isobe et al., 2002; Senjyu et al., 2006). For example, the numerical tracer experiments conducted by Chang and Isobe (2003) showed that $68 \%$ of the Changjiang River plume is transported into the Tsushima Strait and the extension of these buoyant waters is strongly constrained by the TWWC. In the following contents, we will further synthesize the spatial characteristics and driving mechanisms of the Changjiang River plume in summer and winter, respectively.

\section{Changjiang River Plume in Summer}

The freshwater that rushes out of the Changjiang estuary is arrested by the northward coastal current and northeastward flowing TWWC and widely broadened to the southeast, east, and northeast over the shelf region in the surface layer (Hwang et al., 2014). There is weak bidirectional southwestward and northwestward extrusion of these buoyant waters observed over the coastal seas off Zhejiang and over the Subei Shoal (Kim et al., 2009; Bai et al., 2013; Zhu et al., 2015; Zhang et al., 2020). However, this southwestward branch of the plume cannot travel further southward into the Taiwan Strait (Wu et al., 2018b). The entirety of the plume, which widely spreads over the central and northern ECS and southern YS shelves (Lie et al., 2003), turns northeastward over the shelf to the east of the $50-\mathrm{m}$ isobath and flows toward Cheju Island (Chen et al., 2008). The behavior of the plume in the coastal seas to the west of the $50-\mathrm{m}$ isobath is different from that over the shelf in depths $>50 \mathrm{~m}$ since the coastal waters are better mixed than those offshore, which is further described below.

\section{Bulge Circulation}

Numerous numerical simulations and observations have clearly shown that the buoyant waters from the Changjiang River plume are partially mixed with the saltwater being stored in a bulge over the shelf to the west of the 50-m isobath (Chang and Isobe, 2003; Shan et al., 2009). This bulge, which is enveloped by sharp density fronts ( $\mathrm{Lu}$ and Shi, 2007), usually bifurcates at the head of the submerged valley that is delineated by the $50-\mathrm{m}$ isobath over the shelf to the southeast of the Changjiang Estuary and then extends northward into the Subei Shoal, southwestward to Hangzhou Bay and then the coastal seas off Zhejiang (Du et al., 2011) (Figure 3). 

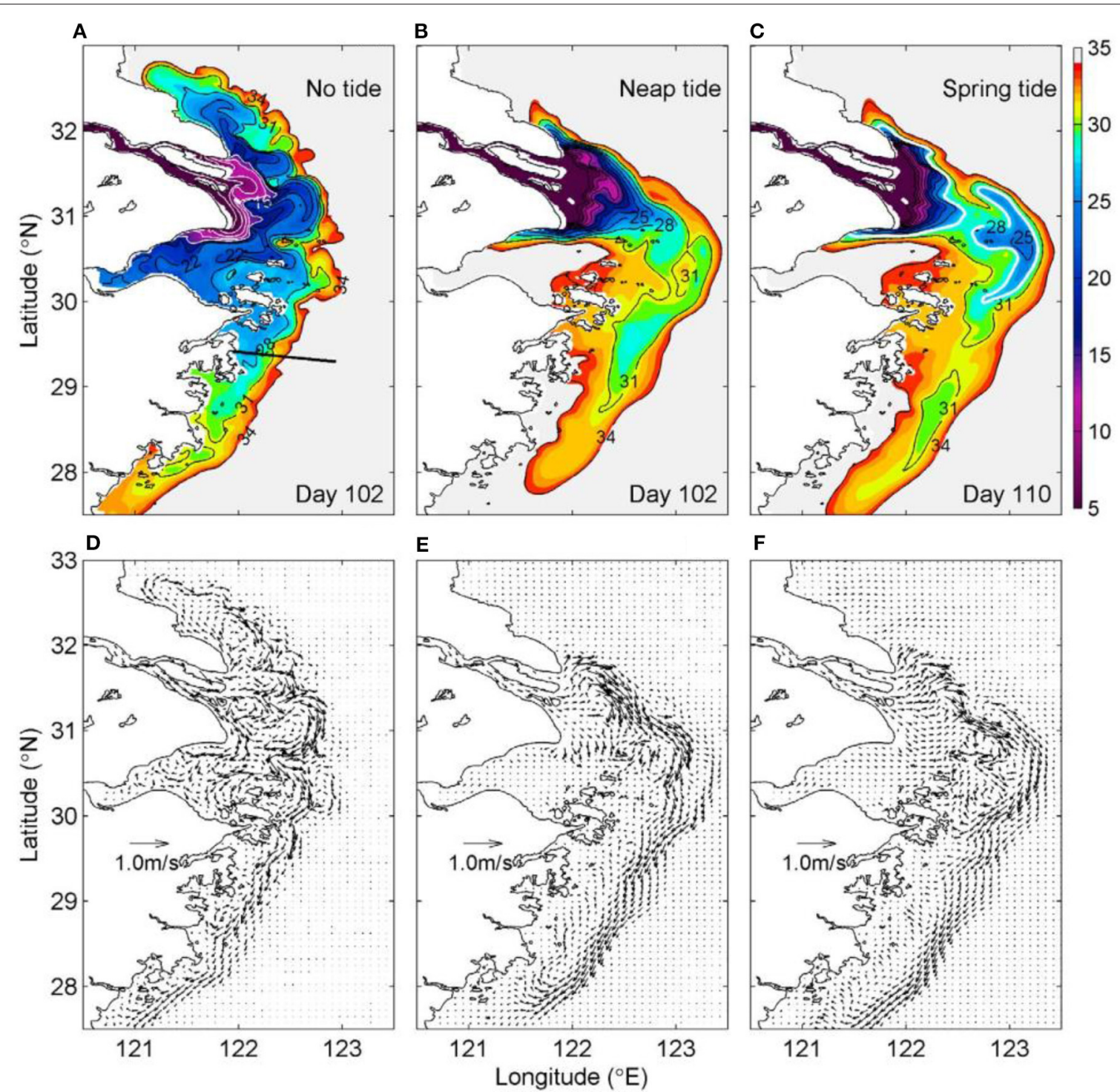

FIGURE 3 | Distributions of (A-C) surface salinity and (D-F) surface currents, respectively, under the condition with (A,D) low discharge without tides, and low discharge with tides during (B,E) neap and $\mathbf{( C , F )}$ spring tide periods. The contour interval for surface salinity distributions in $\mathbf{( A - C )}$ is 3 psu. This figure is adapted from Li and Rong (2012).

The majority of these plume waters then extend northeastward toward the central ECS shelf and interact with the TWWC.

The characteristics of the circulation of this bidirectional extruding bulge is critically determined by tides ( $\mathrm{Wu}$ et al., 2018b). The Changjiang River plume in the coastal areas off the estuary disperses eastward and southeastward in the form of "cloudy patches" and that the dispersion direction varies coherently with tides, when steady winds force estuarine and coastal circulations (Shi and Lu, 2011). The strong tidal mixing over the shallow Subei Shoal suppressed the northward extrusion of Changjiang River plume (Wu et al., 2011). The bulge also considerably varies with the spring-neap tide transition (Figure 3), and is mainly limited in the coastal seas to the west of the $30-\mathrm{m}$ isobath during spring tides and extends further eastward during neap tides when tidal rectification and tidal asymmetry are weak. Tidal asymmetry has been found to establish high pressure at the head of the submerged valley, and the plume is thus guided to extend northeastward at $\sim 122.5^{\circ}$ E. Although its magnitude is much weaker than that in the southward and northeastward branches, tidally induced Stokes drift transports a small portion of the shallow Subei Shoal in winter (Wu et al., 2014), and the wind can only affect this northward extrusion during the neap-tide period.

Tides also increase the amount of freshwater trapped by the bulge (Figure 3; Li and Rong, 2012; Rong and Li, 2012). The bulge circulation is stabilized and its ballooning is suppressed with time (Figures 3B,C,E,F). Detachment of buoyant waters from the plume occurs during the transition period from 
neap to spring tides, when the stratification of the partially mixed plume waters is destroyed and buoyant water patches form, while variation of the Changjiang River discharge rate cannot greatly influence this process of detachment. However, the numerical simulation by Yuan et al. (2016) showed that although the buoyant plume neighboring the Changjiang Estuary instantly (within 1 day) responds to variation in Changjiang River discharge, it takes $\sim 15$ days for the offshore branches of this plume to respond in summer. Thereby, the response of the detachment of buoyant plume to the changing discharge rate should be further investigated.

Winds may also play a crucial role in detaching buoyant waters during the growth of the bulge (Xuan et al., 2012). Windinduced mixing and upwelling along the edge of the bulge causes saltwater to detach the buoyant waters over the $30-\mathrm{m}$ isobath. This detachment mainly occurs during the period when the speed of southwesterly winds exceeds $8 \mathrm{~m} \mathrm{~s}^{-1}$. Thus, the characteristics of the complicated bulge circulation and its dynamics also necessitate further study (Wu et al., 2018b).

\section{Far-Field Plume}

Over the ECS shelf to the east of the $50-\mathrm{m}$ isobath, the interaction between the Changjiang River plume and shelf currents is associated with the complicated wind and tidal patterns and the remote influence of previously introduced shelf currents, which alter the pathway of the plume (Figure 4). For example, the long-term satellite observations (Kim et al., 2009, 2014) of Chlorophyll- $a$ indicated that the eastward motion of the Changjiang River plume lags behind the variations in river discharge by about 1 to 2 months. Bai et al. (2015) adapted and validated the advanced satellite-derived salinity algorithm in Bai et al. (2013) and reported strong interannual variability in the distribution of the Changjiang River plume (Figure 4), which was partially identified in some earlier satellite observations (Ahn et al., 2008). In addition to the most frequently observed northward and northeastward pathways, Bai et al. (2015) identified two unusual pathways of the Changjiang River plume, which flows into the Cheju and Tsushima Straits without residing over the shelf and flows southeastward in the central ECS (Types 2 and 3 in Figure 4). The plume area estimated in that study is regulated by the intensity of river discharge and winds over the shelf. The arrival of typhoons may also play an important role in altering the variability of the pathways of this plume. For example, Oh et al. (2014) and Hong et al. (2016) proposed an extensive northward extrusion of the Changjiang River plume into the YS in 2012. The velocity records of July 2015 further showed that typhoons could even bend the Changjiang River plume to flow southwestward along the Zhejiang coast (Zhang et al., 2018c).

Changjiang River plume extends eastward in the form of patches of low-salinity water instead of as a tongue-shaped plume extending toward Cheju Island (Lie et al., 2003), and it intensifies the TWWC and TSWC (Chen et al., 2008). The baroclinic instability associated with the extensive density fronts enveloping these massive buoyant waters facilitates the eastward transmission of the Changjiang River plume through buoyant eddies that detach from its edge, while the southerly summer monsoon enhances this detachment. The strong tides over the ECS shelf suppress this baroclinic instability, while the detachments of low-salinity water patches are primarily caused by the spatially non-uniform southeasterly wind (Ge et al., 2015). However, the extensive tide-induced vertical mixing in the northern ECS shelf tends to enhance the meandering of buoyant waters off the Subei Shoal and displaces the plume to the north toward the YS (Type 2 in Figure 4). The formation of low-salinity water patches of the plume is induced by increased vertical mixing, especially during the spring-tide period (Moon et al., 2010). The freshwater content of these patches is highly dependent on the intensity of winds, which contributes to the variation of the motion of the plume by altering winddriven Ekman transport, and a synoptically weakened southerly summer monsoon facilitates the southeastward displacement of the buoyant plume (Moon et al., 2012; Chang et al., 2014). There is not close correlation between the changes in the Changjiang River discharge and the pathway of the Changjiang River plume in the central ECS, although the area of the buoyant plume in the central ECS has been observed to vary closely with the discharge rate (Bai et al., 2015).

\section{Changjiang River Plume in Winter}

When flushing out of the estuary, the cold and buoyant waters from the Changjiang estuary are constrained in the coastal seas to the west of the 30-m isobath and advected southwestward in form of the Zhe-Mini Coastal Current (ZMCC) toward the Taiwan Strait (Guan and Fang, 2006). This extensive coastal current, which may be identified by surface temperature and salinity (Gao et al., 2009; Wu et al., 2018b), and the mud belt (Bian et al., 2013; Li et al., 2013) off Zhejiang and Fujian coasts, can be seen in winter. The intensity of the ZMCC in February 2012 was quantified to be $\sim 0.215 \mathrm{~Sv}$ by Wu et al. (2013) using phase-averaging technology. The tidally induced residual current roughly contributes $\sim 0.12 \mathrm{~Sv}$ to the transport of ZMCC ( $\mathrm{Li}$ and Rong, 2012).

Along its path to the Taiwan Strait, the baroclinicity induced by this extensive buoyant plume stimulates the upshelf motion of shelf waters beneath the TWWC and alters the connectivity between the northern SCS and southern ECS (Hu et al., 2010). The baroclinicity from this plume facilitates the formation of the upshelf motion of waters beneath the TWWC, even when downwelling-favorable winter monsoon prevails (Qiao et al., 2006). It has also been reported that a portion of these buoyant waters extrudes northwestward along the coastline of the Subei Shoal in the southern YS to form Subei Coastal Waters (Wu et al., 2018a), whose underlying dynamics will be synthesized below.

Although the buoyant waters from the Changjiang River can be seen off the Zhejiang and Fujian coasts, its southward pathway with the ZMCC showed an extensive meandering that excites synoptic cross-shelf water exchanges (Yuan et al., 2008; He et al., 2010; Bai et al., 2013). The concurrent transport of the northward Kuroshio intrusion from the shelf to the northeast of Taiwan and the TWWC establish water-column stratification over the shelf to the east of the $50-\mathrm{m}$ isobath off the Zhejiang and Fujian coasts, where the tidal wave diverges ( $\mathrm{Wu}, 2015)$. The tidal current and associated mixing are minimized in the coastal 


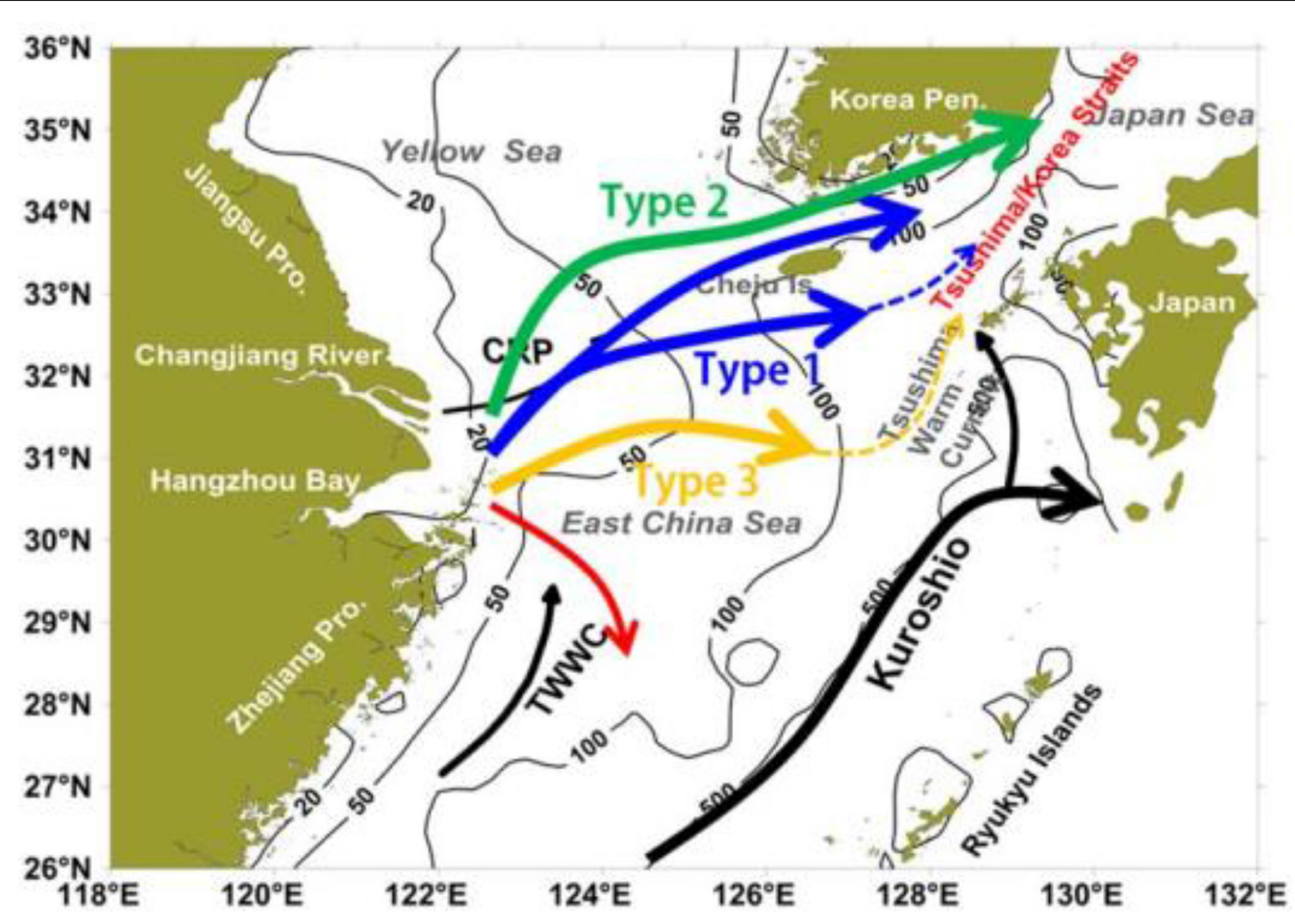

FIGURE 4 | Schematic pathways (colored arrows) of the three types of Changjiang River Plume identified from the 31 psu isohalines. The dashed arrows in blue and yellow signify plume water higher than the 31 psu would have advected by the Tsushima Warm Current to the Tsushima-Korea Straits. The red arrow shows the occasional movement triggered by typhoons. This figure is adapted from Bai et al. (2015), and Type 1 stands for the most frequently observed pathway of the plume, while Type 2 shows the pathway of buoyant waters when the buoyant waters are extensively advected toward Tsushima Strait, without residing over the shelf. Type 3 is rarely observed southeastward motion of the buoyant plume.

areas where a divergence occurs, which stimulates the cross-shelf penetration of two cold-water tongues. The penetration of these shelf waters then induces the offshore export of coastal waters carried by the ZMCC through the joint effect of baroclinicity and relief (JEBAR). This scheme explains the quasi-stationary or lesspropagational cross-shelf water exchanges along the Zhejiang and Fujian coasts (Yuan et al., 2010). This cross-shelf meandering of the coastal current seems not to be governed by frontal instability, and interestingly, fluctuations in temperature but not salinity are a prerequisite for extensive cross-shelf water exchanges, although the appearance of the buoyant plume was found to play an essential role in maintaining the extensive southwestward flow of the ZMCC (Wu et al., 2013).

\section{COASTAL CURRENTS IN THE ECS AND SOUTHERN YS}

\section{East China Sea Coastal Current (ECSCC)}

The variations of coastal circulation in the ECS are jointly driven by monsoons, tides, and the buoyancy forcing from the extensive Changjiang River discharge (Lie and Cho, 2016; Wu et al., 2018b). In general, coastal circulation over the shelf shallower than $50 \mathrm{~m}$ generally flows northeastward in summer and southwestward in winter (Lee and Chao, 2003; Ge et al., 2013; Gan et al., 2016), although extensive synoptic variation has also been observed (Xuan et al., 2016a). The instabilities associated with this current may stimulate notable cross-shelf water exchange in both seasons (Yuan et al., 2005, 2008; He et al., 2010).

The northeastward coastal circulation has been found to generate the upshelf intrusion of shelf waters from the bottom layers of the TWWC, forming a distinct and extensive cold water belt off the Zhejiang and Fujian coasts in summer (Hu and Wang, 2016). In winter, the ZMCC carries $~ 90 \%$ of the Changjiang River discharge (Wu et al., 2013) into the Taiwan Strait (Shen et al., 2017), which modulate the intensity of the TSC through the formation of a zonal density front in the strait (Chen and Sheu, 2006). Along its path, these cold and buoyant waters are vertically well mixed and form a sharp density front with the northeastward flowing TWWC over the outer shelf in winter (Huang et al., 2010).

The characteristics of coastal currents in the ECS are partially synthesized in Guan and Fang (2006) and Hu and Wang (2016), which were important references in our review, especially for studies prior to 2010. In this section, we focus more on the detailed dynamics that govern the cross-isobath transport, and pay more attention on the coastal circulations specifically in the ECS, instead of the entire China Seas.

It has long been recognized in 1990s (Liu and Su, 1991) that the possible forcing mechanisms driving the summer upwelling off the Zhejiang coast include the upwelling favorable southerly monsoon, upward lifting of the shoreward intrusion of the Kuroshio Current from the shelf to the northeast of Taiwan, 
shoreward and upward movements of the TWWC induced by bottom friction, and the response of the TWWC to the regionally diverging isobaths. It was also suggested that upwelling could be divided into inshore and offshore segments (roughly divided by the $70-\mathrm{m}$ isobath), with wind forcing dominating the upwelling process of the inshore area and the TWWC driving the upwelling in the offshore region. Subsequent numerical simulations and observations in the 2000s further confirmed the importance of winds and TWWC in generating the upwelling along the ECS coast (Jing et al., 2007; Wei et al., 2007).

These previous studies have proposed that upwelling does not uniformly occur along the ECS coast, and the detailed dynamics underlying this upwelling circulation are progressively revealed in the recent decades. The upshelf intrusion of shelf waters is intensified on the lee side of coastal promontories along the Zhejiang and Fujian coasts (Chen et al., 2014; Liu and Gan, 2014) as well as at the head of the submerged valley in the central ECS shelf and to the southeast of the Changjiang Estuary (Liu and Gan, 2015; Yuan et al., 2017), where a cold water center with high primary productivity is frequently observed (Shi and Wang, 2012). That upwelling in that submerged valley is strengthened by the baroclinicity of waters imposed by the extensive presence of buoyant waters from the Changjiang River discharge ( $\mathrm{Zhu}$, 2003), and it is considered to be the onshore branch of the TWWC over the shelf to the east of the $50 \mathrm{~m}$ isobath (Wang et al., 2019a). This spatially irregular distribution of upwelling circulation has been frequently reported in recent decades, and we have now recognized the importance of topography as well as tidally induced mixing in generating upwelling in the ECS. For example, field observations and numerical simulations by Lü et al. (2006) have shown that the upslope intrusion of shelf waters in the vicinity of the Changjiang Estuary is mainly induced by a cross-frontal density gradient that is compensated by extensive tidal mixing. Liu and Gan $(2014,2015)$ proposed that the onshore intrusion of shelf waters on the lee-side of Zhoushan Islands and at the head of the submerged valley is not merely induced by bottom Ekman transport but is generated by the alongshore variation of the meridional pressure gradient, which is exerted by the response of the coastal current to the variation in bottom topography.

Interestingly, although we have recognized that it is mainly the northeasterly wind that prevails in the ECS and that a strong southwestward flowing ZMCC characterizes the coastal circulation in winter (Wu et al., 2013), the downslope export of coastal waters due to coastal Ekman dynamics has rarely been reported. For example, previous studies like those of Qiao et al. (2006), Jing et al. (2007), and references therein have suggested that although both the wind and ZMCC favor the downwelling of shelf waters, it is mainly the upshelf intrusion of shelf waters due to the northeastward flowing TWWC that is observed $(\mathrm{Hu}$, 1994).

Some previous studies have focused on the dynamics governing the formation of this upwelling circulation in winter, and tides, as well as the buoyant nature of the coastal currents, have been found to play predominant roles. For example, the numerical simulation and field observations by Qiao et al. (2006) revealed that the sharp density front between the ZMCC and TWWC, due to extensive buoyant discharge from the Changjiang Estuary, facilitates the formation of an extensive cross-front baroclinic pressure gradient that drove upwelling off the Zhejiang coast. Tidal currents extend the river plume further to the southwest and contribute to the formation of upwelling. The northeastward flowing TWWC obstructs the pathway of the ZMCC, the associated density front, and the upwelling of deep shelf waters. Upwelling in the coastal area of the ECS is thereby a year-round phenomenon, with maximum and minimum upward velocities in summer $\left(\sim 10^{-2} \mathrm{~ms}^{-1}\right)$ and winter $\left(\sim 10^{-3} \mathrm{~ms}^{-1}\right)$, respectively (Jing et al., 2007). The recent long-term observations by Huang et al. (2016) over the shelf to the east of Zhejiang in the central ECS have clearly shown that the cross-isobath transport of shelf waters varies coherently with the along-shore velocities of the ZMCC. More importantly, that study proposed that shelf velocities also present extensive synoptic and intra-seasonal variability and suggested that the along-shore geostrophic current may play a more important role in generating the cross-shore water exchange than the role of bottom friction.

\section{Yellow Sea Coastal Current (YSCC)}

The coastal current in the southwestern YS over the shallow Subei Shoal was named as the Yellow Sea Coastal Current (YSCC), which, together with the ECSCC, comprises the China Coastal Current system (Guan and Fang, 2006). In the water column, it is recently proposed that the observed current profiles demonstrate a clockwise rotation, probably due to the "horizontal diffusion of geostrophic vortex stretching” (Song et al., 2019). The YSCC was considered to be a year-round southward flow (Lie and Cho, 1994), and the southward YSCC in winter is generated by the baroclinicity of the fresher waters carried by the Lubei Coastal Current (Wei et al., 2016) or Bohai Sea Coastal Current (Sun et al., 2018) from further north of the Shandong Peninsula. In summer, it is formed by the baroclinicity from the YSCM in the Yellow Sea Trough (Xia et al., 2006) to flow southeastward along the eastern flank of the Subei Shoal (Lie and Cho, 2016).

Yuan et al. (2008) questioned the conclusions of the flow pattern of the YSCC and suggested that the YSCC could be reversed to flow northwestward along the coastline of the Subei Shoal in summer, as also revealed by some simulations in the recent decades (Qiao et al., 2011; Wang et al., 2013b; Shi et al., 2016). A northward extending buoyant plume associated with upwelling in the summers of 2008 and 2009 was observed over the Subei Shoal (Yuan et al., 2017). This northwestward YSCC in summer, accompanied with the southeastward flow in winter, indicates a seasonal reversal of the flow direction, and this seasonal reversal is proven by the in-situ hydrography observations (Wei et al., 2016) and some recent numerical simulations (Gan et al., 2016).

Tides have recently been considered to be another important driving force that alters the circulation over the Subei Shoal. The density front, which is established by extensive tidal mixing over the shelf surrounding the shallow Subei Shoal, generates upwelling of shelf waters along its eastern flank in summer (Lü et al., 2010; Liu and Gan, 2016). This upwelling may result in cold surface waters that are most frequently observed when southerly 
winds prevail (Zhu et al., 2018c). The formation of these cold surface waters is also impacted by the spring-neap tides (Liang et al., 2018). The water column is stratified during neap tides, while during the spring tides, sea surface temperature is at a minimum, which implies strong vertical mixing. YSCC along the eastern flank of the Subei shoal flows southeastward along the 30-m isobath (Xia et al., 2006; Wang et al., 2013a). However, the Lagrangian drifters released over the Subei Shoal clearly showed a northeastward floating trajectory, which is generally perpendicular to the southeastward Eulerian residual current, given that the impact of the southerly summer monsoon exceeds that of the residual current due to increased bottom friction from the extensive tidal currents.

The high-resolution numerical simulation by Xuan et al. (2016b) showed that the tidally induced residual current flows northwestward along the coastline of the Subei Shoal and reverses to the southeastward along the $50-\mathrm{m}$ isobath over the eastern flank of the Subei Shoal (Figure 5A). The authors considered the offshore branch of this current as the YSCC, which exhibits clear seasonal variability. The inshore branch is named as the Tide-Induced Coastal Current (TICC), and it was considered to be a year-round northwestward current. The observations and numerical simulation (Wu et al., 2018a) for the circulation in December 2016 and January 2017 also clearly showed a northwestward current flowing against the northerly wind along the coastline of the Subei Shoal (Figure 5B). The tidal stress induced by the propagation of a Poincaré wave, together with the rotation of the earth, forces the northwestward current along the coastline of Jiangsu, while tidally strengthened bottom friction suppresses the windforced current. The standing wave imposed by the collapsing of tidal waves from the YS and ECS modulate this coastal current, resulting in an eastward flow in the cross-shore direction. This northward current is generated by the Stokes drift due to the propagation of tidal waves ( $\mathrm{Wu}$ et al., 2014).

The numerical simulation by Wang et al. (2017b) exhibited a different winter flow pattern from that of Xuan et al. (2016b) and $\mathrm{Wu}$ et al. (2018a) by taking those buoyant waters from the minor rivers along the coastline of Jiangsu. Although the tidally induced residual current was still suggested to play a critical role in modulating the interactions between the YSWC and YSCC in winter, Wang et al. (2017b) considered that the currents over the Subei Shoal mainly flow southeastward in winter and that these freshwaters are merely from the rivers with minimal discharge along the Subei coast, instead of the Changjiang River plume, since the variations of salinity is insensitive to the discharges of Changjiang River. This finding contradicts those of Wu et al. (2014), Oh et al. (2014), and Xuan et al. (2016b), in which the Changjiang River plume was considered to be the major source of these freshwaters. The recent numerical simulation using water ages indicated that the minimum salinity of these fresher coastal waters lags behind the peak in Changjiang river discharge by about 2 months in summer, and these waters reside over the shallow Subei Shoal in winter (Zhu and Wu, 2018). Taking this lagged response of the circulations over the Subei Shoal to the river discharge from Changjiang river into consideration, the roles of buoyancy forcing in altering the YSCC are worth to be further explored.

It can be summarized that the flow pattern of the YSCC, which is the result of complicated forcing conditions associated with the shallow shelf of the Subei Shoal, should be further investigated. According to the contrasting flow patterns of the shallow coastal waters in the vicinity of its eastern flank and the submerged valley to the south, it becomes necessary to further evaluate the YSCC by examining its coastal and offshore branches (Wei et al., 2016; Xuan et al., 2016b; Wu et al., 2018a). The former branch is characterized as Subei Coastal Water (SCW), while the latter is characterized as the YSCC in Xuan et al. (2016b), which interacts with the YSWC/YSCM and the offshore branch of TWWC to the east of the 50-m isobath.

\section{IMPACTS OF CIRCULATION ON HYPOXIA OFF THE CHANGJIANG ESTUARY}

The buoyant plume from Changjiang exports huge amounts of dissolved inorganic nitrogen $(\sim 5,896 \mathrm{Gg} \mathrm{N} / \mathrm{yr})$, phosphate $(\sim 381$ Gg P/yr) (Gao et al., 2008, 2012; Tong et al., 2017; Liu et al., 2018 ) and sediments ( 250 million tons/year) (Yang et al., 2006, 2015) into the ECS. As shown in Figure 6, the nutrients from Changjiang discharge, together with those intruding into the ECS through the Taiwan Strait (Huang et al., 2019) and from the Kuroshio (Chen et al., 1995; Chen, 1996; Lui et al., 2015; Qian et al., 2017; Zhang et al., 2019c; Zuo et al., 2019), played critical roles in stimulating the phytoplankton bloom (Li et al., 2014a; Yu et al., 2018), eutrophication and hypoxia in the coastal water. Chen et al. (2017) proposed that hypoxia usually occurs in the bottom waters in the eutrophication area with the concentration of surface chlorophyll- $a$ exceeds $3.0 \mathrm{mg} \mathrm{L}^{-1}$. The formed hypoxia are destructive to the marine ecosystem (Xu et al., 2015; Zhu et al., 2016b) in ECS (Chen et al., 2003; Wang et al., 2012; Qian et al., 2017; Wei et al., 2017a; Zhou et al., 2017; Zhang et al., 2018b; Wang et al., 2019c; Wang et al., 2019b; Zhang et al., 2019c; Chen et al., 2020a) and the YS (Zhai et al., 2020). It is generally considered that during the recent decades from 1980s to 2010s, there is an accelerated anthropogenic nutrient loading, and occurrence of eutrophication (Wang J. et al., 2015; Wang et al., 2016, 2018) and hypoxia (Wu et al., 2020) in the coastal waters (Liu et al., 2018; Chen J. et al., 2020). The recent overview by Chen J. et al. (2020) is recommended as an important reference that comprehensively synthesized the nutrient dynamics and biogeochemical processes, and here we focus on the impact of circulation dynamics to the changing hypoxia condition in the coastal seas of the ECS. The impact of circulation on the biogeochemical processes, not only revealed by its redistribution (Wang et al., 2019b; Wei et al., 2020) of nutrients and the elevated Redfield ratio (Wang J. et al., 2015; Chen et al., 2017; Liu et al., 2018), but also its changes on the stratification, residence time and ventilation of the shelf waters (Rabouille et al., 2008; Zhu et al., 2016a; Luo et al., 2018; Zhang et al., 2019c) will be overviewed in this section.

Hypoxia, usually with acidification of the seawaters (Wei et al., 2017b, 2020), generally occurs in the coastal seas neighboring 

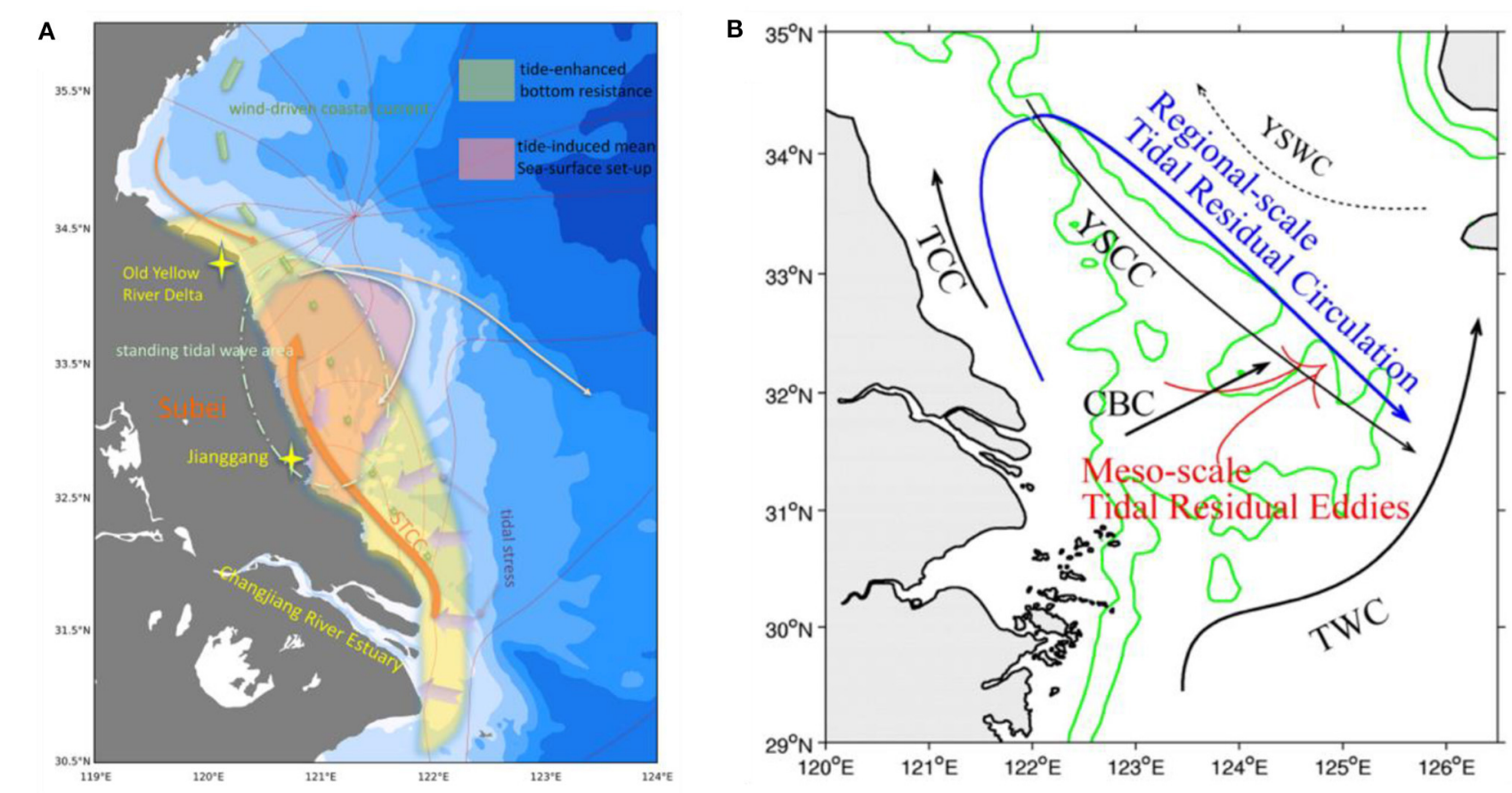

FIGURE 5 | (A) Sketch map of residual transport over the Subei Shoal and its controlling mechanisms by the Subei tide-induced coastal current (STCC), which is raised from tidal stress (pink arrows) in the coastal seas to the north of Changjiang Estuary. The thin red lines indicate co-phase lines for the $\mathrm{M}_{2}$ tide with an interval of $30^{\circ}$. The wind driven coastal current in winter is indicated by the green arrows, and the circulations over the eastern flank of Subei Shoal is indicated by the yellow thin lines. This figure is adapted from Wu et al. (2018a). (B) Tidal residual current and mean flow over the Subei Shoal. Meso-scale tidal residual eddies (red arrow) and regional-scale tidal residual circulation (blue arrow) show the patterns of the tidal residual current across and around the Subei Shoal. The structure of mean flows (five black arrows) is composed by Taiwan Warm Current (TWC), YSCC, Changjiang Bank Current (CBC), Tidal-induced Coastal Current (TCC), and YSWC. This figure is adapted from Xuan et al. (2016b).

the $30 \mathrm{~m}$ isobath over the shelf. It strengthens from the late spring to summer (Zuo et al., 2019) and peaks in August (Zhu et al., 2011, 2017). There are also observations showing that the hypoxia can occasionally last longer to the midautumn (Wang et al., 2012; Chen C. C. et al., 2020). In winter, the buoyant waters are well-ventilated and hypoxia is thereby prevented (Zheng et al., 2016; Liblik et al., 2020). It is considered that the physical environment favors the development of hypoxia in summer, when the Changjiang river discharge maximizes (section Changjiang estuarine circulation), an intensified northeastward TWWC appears (Wang et al., 2012), upwelling of the shelf waters is established and the coastal waters are more stratified (Zheng et al., 2016; Chen et al., 2017). From June to August, the hypoxic waters mainly expand northeastward from the coastal seas to the east of Zhejiang and where mudbelt is observed (Zhang et al., 2019c). This hypoxia is mainly established by the Changjiang buoyant plume and intrusion of Kuroshio subsurface water (Zhang et al., 2019c), while the northeastward expansion is largely related to the strengthening of the northeastward TWWC and advances of upwelling circulation (Wei et al., 2011). Stratification of the coastal waters responses to circulation/discharges within $\sim 35 \mathrm{hr}$ ( $\mathrm{Ni}$ et al., 2016), followed by an response of the bottom dissolved oxygen to changes of stratification is generally $\sim 6$ to $\sim 50 \mathrm{~h}$ (Zhang et al., 2018b). The stratification is also sensitive to changes in the wind intensity and direction (Chen et al., 2015; Zheng et al., 2016; Zhou et al., 2017), which jointly regulate the stratification, coastal current and pathway of the buoyant plume.

Kuroshio intrusion mainly regulates the hypoxia by increasing the residence time of the bottom coastal waters (from $\sim 11$ to $\sim 40$ days) in summer (Zhang et al., 2019c). However, the intrusion also alleviates the hypoxia through carrying shelf waters with a higher concentration of dissolved oxygen (Luo et al., 2018; Zuo et al., 2019). It is also found that the incoming Kuroshio waters is deoxygenating and acidifying (Lui et al., 2015). The overall effect of the Kuroshio intrusion is to increase the intrusion of nutrients and strengthen the stratification intensity over the shelf. Thus, the summer hypoxia have a tendency of being worsened under the influence of the Kuroshio intrusion (Lui et al., 2014).

In the synoptic timescale, the increment of Changjiang river discharge is believed to stimulate the expansion of hypoxia (Zheng et al., 2016; Zhou et al., 2017), although there are also studies suggested that the changes in hypoxia are not response to the changes in the river discharge instantly (Chen et al., 2015). The offshore detachment of buoyant waters in form of "cloudy patches" synthesized in the section 3.1, played critical roles in regulating the hypoxia condition (Liblik et al., 2020; 


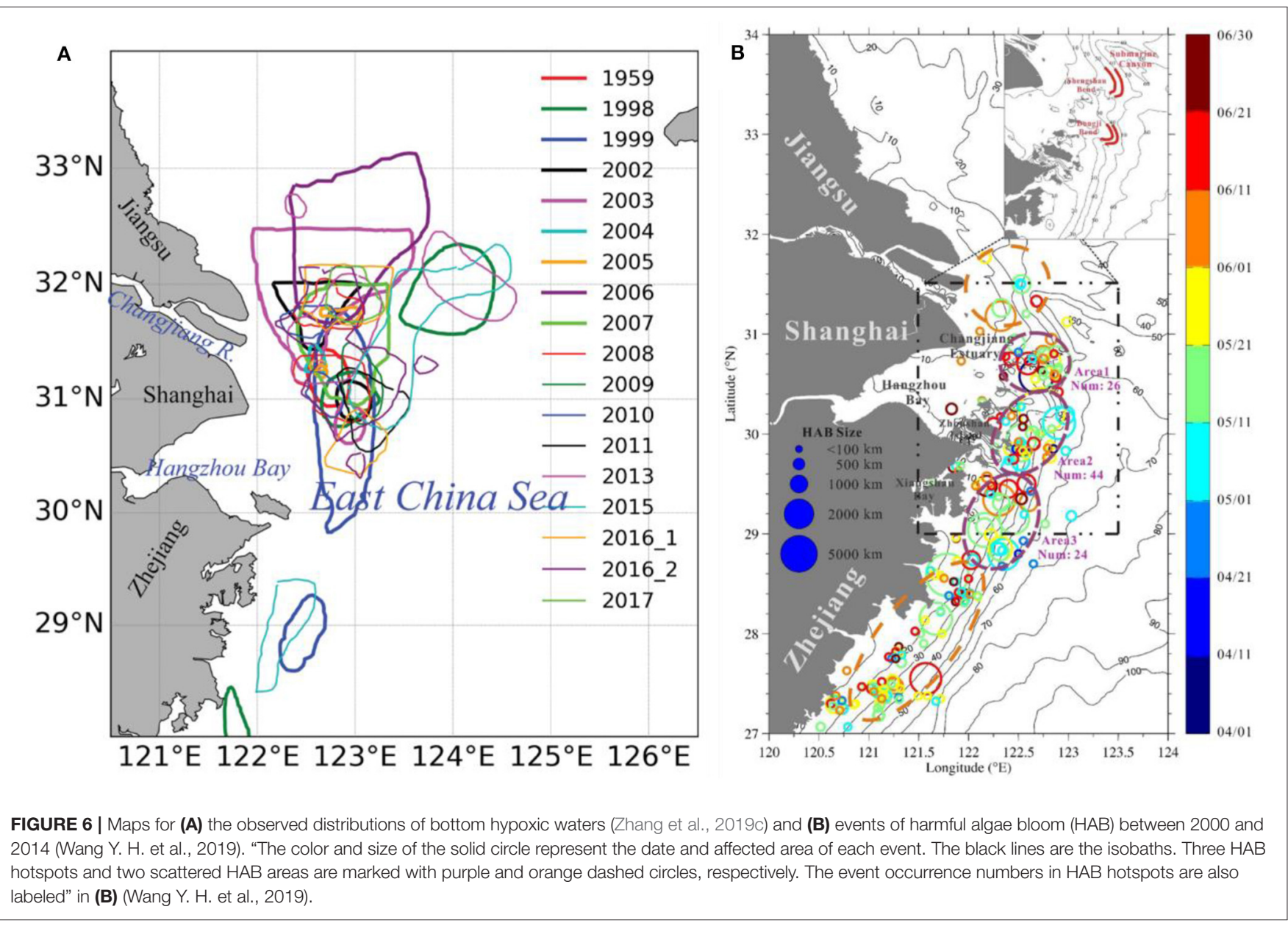

Wei et al., 2020). The phytoplankton bloom sealed inside these patches with relatively stable environment and the organic debris favor the formation of hypoxia. This offshore detachment of buoyant plume is also found to play critical roles in regulating the algal bloom and formation of high chlorophyll- $a$ centers (Figure 6B) in the coastal seas (Wang Y. H. et al., 2019). In summer, the hypoxia off the Changjiang Estuary is dissipated by the arriving typhoon (Wu et al., 2005), which greatly alters the pathway of buoyant plume from Changjiang and strengthens vertical mixing (Zhu et al., 2016a). However, the extensive vertical mixing and the excessive nutrient loading due to the increased river discharge during the typhoon period greatly stimulate the establishment of phytoplankton bloom after typhoon. This process boosts the restoration of hypoxia within several days after typhoon landing and the waters are re-stratified (Wang et al., 2017a). This timescale is shorter than the formation of hypoxia due to moderate changes in winds ( $\mathrm{Ni}$ et al., 2016). The changes of hypoxia condition, in a shorter timescale, is also found to vary in a semi-diurnal tidal period, e.g., $\sim 12 \mathrm{~h}$, due to the combined effect of the bottom topography and spatial irregularity of the tidal extrusion distance off the Changjiang estuary (Zhu et al., 2017; Zhang et al., 2019c).

\section{SUMMARY AND PROSPECTS}

\section{Summary}

This manuscript synthesizes the recent studies on the circulation in the Changjiang Estuary and the neighboring circulation in the coastal East China Sea and southern Yellow Sea (Figure 7). The exchange flows among the branches, channels, and passages in the Changiiang Estuary have been found to be greatly influenced by seasonal variation in riverine discharge while also being regulated by the tides. It has been found that over $95 \%$ of the riverine runoff rushes into the East China Sea through the South Branch, while the greatly diminished discharge rate in winter (i.e., dry season) facilitates the extrusion of saltwater and the injection of saltwater from the North Branch to the South Branch. This upstream extrusion oscillates with the flood and ebb tides and its amplitude increases during the spring-tide period, while the byproducts of these propagating tidal waves have been recently recognized to play important roles in regulating the estuaryward extrusion of shelf waters. The northerly wind facilitates the injection of saltwater from the North Branch to the South Branch.

The buoyant waters from the South Branch have been found to be evenly partitioned toward the South and North Channels. Gravitational circulation, forced by the density gradient between 

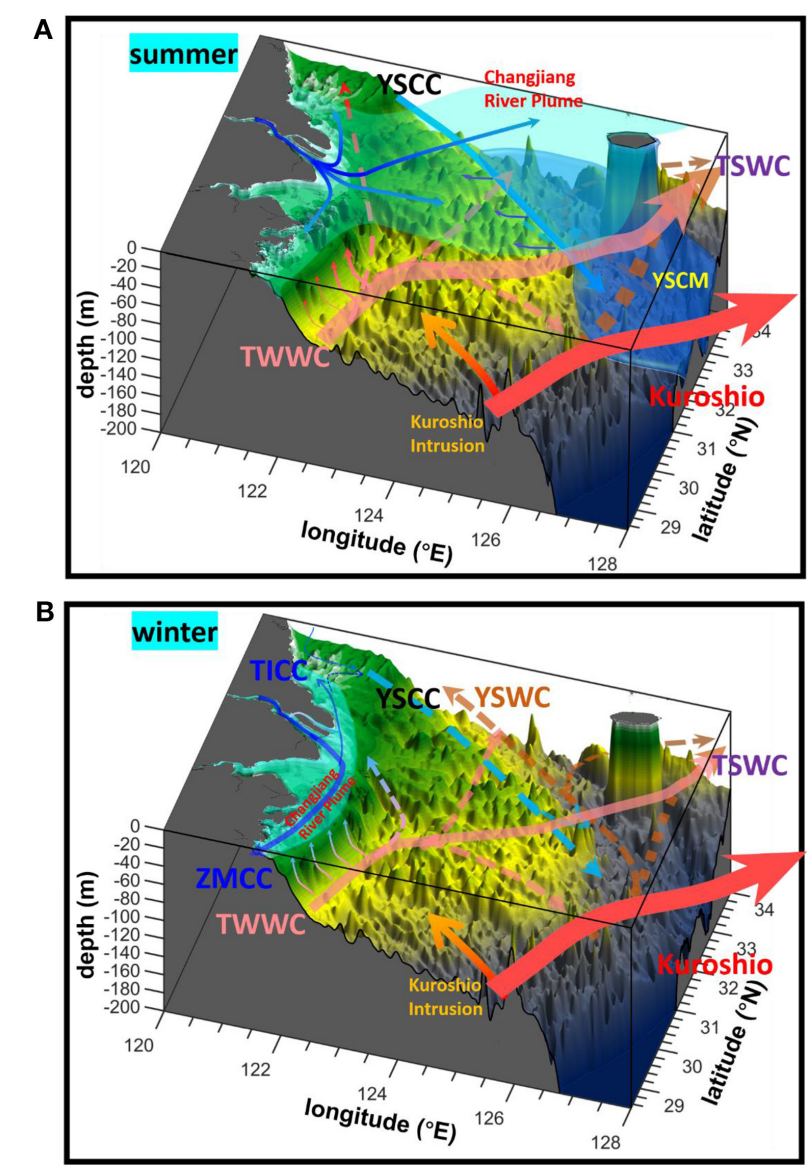

FIGURE 7 | Schematic of general circulations around the Changjiang Estuary in (A) summer and (B) winter. The shelf currents over the ECS are indicated by the vectors with warm colors, and the buoyant plume, TICC and YSCC are shown by the cold colors. The dashed lines indicate uncertainty in observed pathway of circulations in the ECS and southern YS.

the buoyant waters from riverine discharge and the denser shelf waters, intensifies the exchange of these flows. The jetty spur that borders the North Passage acts to extensively redistribute the freshwaters in the lower estuary, resulting in great circulation complexity. It is generally understood that this construction substantially increases the transport time required for the buoyant waters to travel from the river entrance to the estuary mouth.

In the coastal waters off the estuary, bulge circulation delineated by an extensive density front traps a considerable portion of riverine buoyant waters and mixes them with the waters from the ECS shelf. This bulge broadly expands southwestward toward Hangzhou Bay, southeastward toward the submerged valley, eastward, and northeastward toward the central ECS shelf, and northwestward toward the shallow waters over the Subei Shoal. Thus, the Changjiang River plume plays an important role in regulating the general circulation in the ECS and southern YS. Tides also play important roles in regulating the formation of this bulge. It has been shown that along the edge of the bulge, buoyant waters are shed in the form of "cloudy patches" in response to the variability in tidal and wind forcing and variations in the TWWC. The baroclinicity associated with these shed buoyant waters and the spatial variations of the tides facilitate the cross-shelf export of freshwaters in the coastal seas to the southwest of the Changiiang Estuary.

When southerly winds prevail, the Changjiang River plume generally travels to the northeast and is exported toward the southern YS and Tsushima Strait further to the north. This northward and northeastward motion of the buoyant plume shows extensive spatial variability in the form of notable patches of buoyant waters. The southward motion of the Changjiang River plume is diminished by the northeastward coastal current, which facilitates the formation of the extensive upwelling in the coastal seas off the Fujian and Zhejiang coasts, where the upslope intrusion of colder shelf waters is regulated by the along-shore irregularity of the bathymetry. A northwestward extrusion of buoyant waters from the Changjiang River plume is also observed in the nearshore regions of the shallow Subei Shoal.

In winter, the Changjiang River plume is carried by the ZMCC to flow southwestward in the coastal seas off the Zhejiang and Fujian coasts. Along its pathway, the cold water from the bottom-advected buoyant plume exerts an extensive shoreward pressure gradient, which is balanced by extensive tidal mixing, and stimulates upwelling in the coastal seas off the Zhejiang and Fujian coasts. A minimal portion of these buoyant waters $(\sim 10 \%)$ also extrude northwestward toward the nearshore regions of the shallow Subei Shoal and alter the YSCC, which was recently found to be regulated by the southeastward coastal current from the Shandong Peninsula, the intrusion of the YSWC, and tidal mixing along the eastern flank of the Subei Shoal.

The general circulation associated with the YSCC to the west of the $50-\mathrm{m}$ isobath in the southern YS has been frequently debated in recent decades. A year-round southeastward current over the shallow Subei Shoal has been observed, and the details of its flow pattern have been progressively evaluated, although the underlying dynamics remain unclear. A series of recent observations and high-resolution numerical simulations have suggested that tides play important roles in regulating the YSCC by increasing turbulent mixing and establishing a cross-isobath pressure gradient that facilitates the seasonal reversal of its mainstream flow, and the cross-shore exchanges between the waters in the Subei Shoal and Yellow Sea Trough.

It is considered that the physical environment favors the development of hypoxia, particularly in summer, when the river discharge maximizes, an intensified northeastward TWWC appears (Wang et al., 2012), upwelling of the shelf waters is established and the coastal waters are more stratified. Those physical processes redistribute nutrients, elevate Redfield ratio (Wang J. et al., 2015; Chen et al., 2017; Liu et al., 2018), and further affect the stratification, residence time and ventilation of the shelf waters. Thus, could largely modulate the biogeochemical processes and hypoxia off the Changjiang Estuary.

\section{Prospects}

Although the recent observations and numerical simulations have greatly enriched our understanding of the details of the 
coastal circulation in the ECS and YS as well as circulation in the Changjiang Estuary, it should be noted that the interactions and circulation dynamics governing the estuarine-coastalshelf-slope-Kuroshio current system are still not thoroughly understood due to the complex bathymetry, regional and remote forcing factors, and the wide-spectrum temporal variabilities in this circulation system. These wide-spectrum variabilities are transmitted to the current system over the ECS and southern YS through cross-scale interactive exchange flows, which should be further investigated. Our prospects of future studies on the coastal and estuarine circulations around of the Changjiang Estuary are as follow:

- The detailed mechanisms of, for example, tides in determining the exchange flows in the branches and channels in the Changjiang Estuary are worthy to be further investigated to better reveal the cross-scale interactions (Lu et al., 2015) of the wind-driven shelf circulation and the tidally-modulated estuarine circulations. The roles of tidal-straining, asymmetric tidal mixing ( $\mathrm{Lu}$ et al., 2019), wind-straining and buoyancy run-offs could be investigated in details (Zhu et al., 2018b) to complete the mechanisms governing this multichannel estuary. The coastal, shelf and estuarine circulations must be systematically coupled in a quasi-seamless way, instead of, respectively, taking the coastal and estuarine circulations as the lateral boundary of each other. The synoptic fluctuations in not only the winds around the estuary, but also their remote impacts arriving with the downshelf propagating of, for example, coastally trapped waves (Ding et al., 2018), should be included.

- Given the nutrients carried by the buoyant waters from Changjiang are largely trapped inside the bulge off the estuary, we should further investigate its behavior, includes the residence time of the sealed waters, the processes governing its growth, as well as the dynamical role of bulge in communicating the circulations in Hangzhou Bay and Changjiang Estuarine. The synoptic fluctuation and fate of the far-field plume should be better investigated through measuring the surface salinity in fine-scales by satellite remote sensing and high-frequency profiles by the moored buoy array observations.

- The dynamical role of the TWWC, including the variations of its intensity and meanders in the mainstream should be better observed by a series of multi-functional buoys or regularly performing field cruises by using the phase-averaged method.

\section{REFERENCES}

Ahn, Y. H., Shanmugam, P., Moon, J. E., and Ryu, J. H. (2008). Satellite remote sensing of a low-salinity water plume in the East China Sea. Ann. Geophys. 26, 2019-2035. doi: 10.5194/angeo-26-20192008

Alebregtse, N. C., and de Swart, H. E. (2016). Effect of river discharge and geometry on tides and net water transport in an estuarine network, an idealized model applied to the yangtze estuary. Cont. Shelf Res. 123, 29-49. doi: 10.1016/j.csr.2016.03.028
We should also further clarify the general flow pattern of the YSCC and TICC/SCW, and investigate the impact of the diurnal variations of forces, including not only heat flux but also land-sea breeze, which is recently considered to nonnegligibly modulate the long-term variation of ECS circulation (Yu et al., 2020b).

- The contribution of the various physical processes to the biogeochemical process like hypoxia need to be further clarified and quantified. The interactive multi-scale physical processes should be considered to provide comprehensive understanding on the marine environmental issues in the region.

The accumulation of information based on multiple long-term observations from bottom- or surface-moored instruments, as well as high-resolution numerical simulations, is essential. These high-resolution numerical simulations and accompanying field observations will facilitate the formation of a comprehensive understanding of the exchange flows and their underlying dynamics and mechanisms. Moreover, cautious is required to interpretate the interannual or decadal variabilities of estuarine and coastal circulations over this shallow shelf sea. The rapid changes of forces, including, for example, strong winds (Chai et al., 2020), and the associated near inertial oscillation (Meng et al., 2020) or riverine discharges (Lee et al., 2017; Moon et al., 2019), potentially have the long-lasting influences to overtake the responses of the coastal and estuarine circulations in the lower-frequency.

\section{AUTHOR CONTRIBUTIONS}

$\mathrm{ZL}$ writes the manuscript by integrating the comments and suggestions from JH, HW, JG, ZC, and YD. All authors contributed to the article and approved the submitted version.

\section{FUNDING}

This study was supported by the National Natural Science Foundation of China (41906016 and 41942034), the National Key R\&D Program of China (2018YFC1406302 and 2016YFA0601903), and Science, Technology, and Innovation Commission of Shenzhen Municipality (JCYJ20190809144411368), and the Science and Technology Development Fund, Macau SAR (SKL-IOTSC2018-2020).
Bai, Y., He, X., Pan, D., Chen, C.-T. A., Kang, Y., Chen, X., et al (2015). Summertime Changjiang River plume variation during 19982010. J. Geophys. Res. Oceans 119, 6238-6257. doi: 10.1002/2014JC0 09866

Bai, Y., Pan, D. L., Cai, W. J., He, X. Q., Wang, D. F., Tao, B. Y., et al. (2013). Remote sensing of salinity from satellite-derived CDOM in the Changjiang river dominated East China sea. J. Geophys. Res. Oceans 118, 227-243. doi: 10.1029/2012JC008467

Bian, C. W., Jiang, W. S., and Greatbatch, R. J. (2013). An exploratory model study of sediment transport sources and deposits in the Bohai sea, 
Yellow sea, and East China sea. J. Geophys. Res. Oceans 118, 5908-5923. doi: 10.1002/2013JC009116

Cai, H. Y., Zhang, X. Y., Zhang, M., Guo, L. C., Liu, F., and Yang, Q. S. (2019). Impacts of Three Gorges Dam's operation on spatial-temporal patterns of tideriver dynamics in the Yangtze River estuary, China. Ocean Science 15, 583-599. doi: 10.5194/os-15-583-2019

Chai, C., Yu, Z., Shen, Z., Song, X., Cao, X., and Yao, Y. (2009). Nutrient characteristics in the Yangtze river estuary and the adjacent East China sea before and after impoundment of the Three Gorges dam. Sci. Total Environ. 407, 4687-4695. doi: 10.1016/j.scitotenv.2009.05.011

Chai, X., Liang, X., Zhao, Y., Wu, H., and Wang, Y. (2020). An abnormal sea surface warming event as typhoon bolaven passes the Yellow sea. Acta Oceanol. Sin. 42, 41-50.

Chang, P. H., and Isobe, A. (2003). A numerical study on the Changjiang diluted water in the Yellow and East China seas. J. Geophys. Res. Oceans 108, 1-17. doi: 10.1029/2002JC001749

Chang, P. H., Isobe, A., Kang, K. R., Ryoo, S. B., Kang, H. S., and Kim, Y. H. (2014). Summer behavior of the Changjiang diluted water to the East/Japan sea: a modeling study in 2003. Cont. Shelf Res. 81, 7-18. doi: 10.1016/j.csr.2014.03.007

Chen, C., Zhu, J., Beardsley, R. C., and Franks, P. J. S. (2003). Physical-biological sources for dense algal blooms near the Changjiang river. Geophys. Res. Lett. 30:1515. doi: 10.1029/2002GL016391

Chen, C.-C., Gong, G.-C., Chou, W.-C., and Shiah, F.-K. (2020a). Hypoxia in autumn of the East China Sea. Mar. Pollut. Bull. 152:110875. doi: 10.1016/j.marpolbul.2019.110875

Chen, C.-T. A. (1996). The kuroshio intermediate water is the major source of nutrients on the East China sea continental shelf. Oceanol. Acta 19, 523-527.

Chen, C.-T. A., and Sheu, D. D. (2006). Does the Taiwan warm current originate in the Taiwan strait in wintertime? J. Geophys. Res. 111:C04005. doi: 10.1029/2005JC003281

Chen, C. S., Xue, P. F., Ding, P. X., Beardsley, R. C., Xu, Q. C., Mao, X. M., et al. (2008). Physical mechanisms for the offshore detachment of the Changiiang diluted water in the East China sea. J. Geophys. Res. Oceans 113:C02002. doi: 10.1029/2006JC003994

Chen, C. T. A., Ruo, R., Pai, S. C., Liu, C. T., and Wong, G. T. F. (1995). Exchange of water masses between the East-China-sea and the Kuroshio off Northeastern Taiwan. Cont. Shelf Res. 15, 19-39. doi: 10.1016/0278-4343(93)E0001-O

Chen, J., Li, D., Jin, H., Jiang, Z., Wang, B., Wu, B., et al. (2020). "Changing nutrients, oxygen and phytoplankton in the East China sea," in Changing AsiaPacific Marginal Seas, eds C. T. A. Chen and X. Guo (Singapore: Springer Singapore), $155-178$

Chen, J., Pan, D., Liu, M., Mao, Z., Zhu, Q., Chen, N., et al. (2017). Relationships between long-term trend of satellite-derived chlorophyll-a and hypoxia off the changiiang estuary. Estuar. Coasts 40, 1055-1065. doi: 10.1007/s12237-016-0203-0

Chen, Q., Zhu, J. R., Lyu, H. H., Pan, S. Q., and Chen, S. L. (2019). Impacts of topography change on saltwater intrusion over the past decade in the Changjiang estuary. Estuar. Coast. Shelf Sci. 231:106469. doi: 10.1016/j.ecss.2019.106469

Chen, X., Shen, Z., Li, Y., and Yang, Y. (2015). Physical controls of hypoxia in waters adjacent to the yangtze estuary: a numerical modeling study. Mar. Pollut. Bull. 97, 349-364. doi: 10.1016/j.marpolbul.2015. 05.067

Chen, Y., He, Q., Shen, J., and Du, J. B. (2020b). The alteration of lateral circulation under the influence of human activities in a multiple channel system, Changjiang estuary. Estuar. Coast. Shelf Sci. 242:106823. doi: 10.1016/j.ecss.2020.106823

Chen, Z. Y., Yan, X. H., and Jiang, Y. W. (2014). Coastal cape and canyon effects on wind-driven upwelling in northern Taiwan strait. J. Geophys. Res. Oceans 119, 4605-4625. doi: 10.1002/2014JC009831

Dai, Z. J., Fagherazzi, S., Mei, X. F., and Gao, J. J. (2016). Decline in suspended sediment concentration delivered by the Changjiang (yangtze) River into the East China sea between 1956 and 2013. Geomorphology 268, 123-132. doi: 10.1016/j.geomorph.2016.06.009

Ding, Y., Bao, X. W., Yao, Z. G., Song, D. H., Song, J., Gao, J., et al. (2018). Effect of coastal-trapped waves on the synoptic variations of the Yellow sea warm current during winter. Cont. Shelf Res. 167, 14-31. doi: $10.1016 /$ j.csr.2018.08.003
Du, P. J., Zhang, H., Xiao, W. J., Kang, X., and Guan, Q. L. (2011). Analysis of thermohaline and current distribution characteristics of Zhejiang and Fujian waters in summer. Acta Oceanol. Sin. 30, 71-83. doi: 10.1007/s13131-011-0149-9

Gan, J. P., Liu, Z. Q., and Liang, L. L. (2016). Numerical modeling of intrinsically and extrinsically forced seasonal circulation in the China seas: a kinematic study. J. Geophys. Res. Oceans 121, 4697-4715. doi: 10.1002/2016JC011800

Gao, L., Li, D., and Zhang, Y. (2012). Nutrients and particulate organic matter discharged by the Changjiang (Yangtze river): seasonal variations and temporal trends. J. Geophys. Res 117:G04001. doi: 10.1029/2012JG001952

Gao, L., Li, D. J., and Ding, P. X. (2008). Nutrient budgets averaged over tidal cycles off the Changjiang (Yangtze river) estuary. Estuar. Coast. Shelf Sci. 77, 331-336. doi: 10.1016/j.ecss.2007.09.018

Gao, L., Li, D. J., and Ding, P. X. (2009). Quasi-simultaneous observation of currents, salinity and nutrients in the Changjiang (Yangtze river) plume on the tidal timescale. J. Mar. Syst. 75, 265-279. doi: 10.1016/j.jmarsys.2008.10.006

Ge, J. Z., Ding, P. X., and Chen, C. S. (2015). Low-salinity plume detachment under non-uniform summer wind off the Changiiang estuary. Estuar. Coast. Shelf Sci. 156, 61-70. doi: 10.1016/j.ecss.2014.10.012

Ge, J. Z., Ding, P. X., Chen, C. S., Hu, S., Fu, G., and Wu, L. Y. (2013). An integrated East China Sea-Changjiang Estuary model system with aim at resolving multi-scale regional-shelf-estuarine dynamics. Ocean Dynamics 63, 881-900. doi: 10.1007/s10236-013-0631-3

Guan, B. X., and Fang, G. H. (2006). Winter counter-wind currents off the southeastern China coast: a review. J. Oceanogr. 62, 1-24. doi: 10.1007/s10872-006-0028-8

He, L., Li, Y., Zhou, H., and Yuan, D. L. (2010). Variability of cross-shelf penetrating fronts in the East China sea. Deep Sea Res. Part II Top. Stud. Oceanogr. 57, 1820-1826. doi: 10.1016/j.dsr2.2010.04.008

Hong, J. S., Moon, J. H., Lee, J. H., and Pang, I. C. (2016). Modeling the largest inflow of Changjiang freshwater into the Yellow sea in 2012 with particletracking experiment. Ocean Sci. J. 51, 549-562. doi: 10.1007/s12601-016-0057-1

Hu, D. X. (1994). "Some striking features of circulation in Huanghai sea and East China sea," in Oceanology of China Seas, eds Z. Di, L. Yuan-Bo, and Z. Cheng-Kui (Dordrecht: Springer Netherlands), 27-38.

Hu, J., and Wang, X. H. (2016). Progress on upwelling studies in the China seas. Rev. Geophys. 54, 653-673. doi: 10.1002/2015RG000505

Hu, J. Y., Kawamura, H., Li, C. Y., Hong, H. S., and Jiang, Y. W. (2010). Review on current and seawater volume transport through the taiwan strait. J. Oceanogr. 66, 591-610. doi: 10.1007/s10872-010-0049-1

Huang, D. J., Zeng, D. Y., Ni, X. B., Zhang, T., Xuan, J. L., Zhou, F., et al. (2016). Alongshore and cross-shore circulations and their response to winter monsoon in the western East China sea. Deep Sea Res. Part II Top. Stud. Oceanogr. 124, 6-18. doi: 10.1016/j.dsr2.2015.01.001

Huang, D. J., Zhang, T., and Zhou, F. (2010). Sea-surface temperature fronts in the yellow and East China seas from TRMM microwave imager data. Deep Sea Res. Part II Top. Stud. Oceanogr. 57, 1017-1024. doi: 10.1016/j.dsr2.2010.02.003

Huang, T.-H., Chen, C.-T. A., Lee, J., Wu, C.-R., Wang, Y.-L., Bai, Y., et al. (2019). East China Sea increasingly gains limiting nutrient $\mathrm{P}$ from South China Sea. Sci. Rep. 9:5648. doi: 10.1038/s41598-019-42020-4

Hwang, J. H., Van, S. P., Choi, B. J., Chang, Y. S., and Kim, Y. H. (2014). The physical processes in the Yellow sea. Ocean Coast. Manag. 102, 449-457. doi: 10.1016/j.ocecoaman.2014.03.026

Isobe, A. (2008). Recent advances in ocean-circulation research on the Yellow sea and East China sea shelves. J. Oceanogr. 64, 569-584. doi: 10.1007/s10872-008-0048-7

Isobe, A., Ando, M., Watanabe, T., Senjyu, T., Sugihara, S., and Manda, A. (2002). Freshwater and temperature transports through the Tsushima-Korea straits. J. Geophys. Res. Oceans 107, 2-1-2-20. doi: 10.1029/2000JC000702

Jing, Z. Y., Hua, Z. L., Qi, Y. Q., and Cheng, X. H. (2007). Numerical study on the coastal upwelling and its seasonal variation in the East China sea. J. Coast. Res. $50,555-563$

Kim, H. C., Yamaguchi, H., Yoo, S., Zhu, J., Okamura, K., Kiyomoto, Y., et al. (2009). Distribution of Changjiang diluted water detected by satellite chlorophyll-a and its interannual variation during 1998-2007. J. Oceanogr. 65, 129-135. doi: 10.1007/s10872-009-0013-0

Kim, S. B., Lee, J. H., De Matthaeis, P., Yueh, S., Hong, C. S., Lee, J. H., et al. (2014). Sea surface salinity variability in the East China sea 
observed by the aquarius instrument. J. Geophys. Res. Oceans 119, 7016-7028. doi: 10.1002/2014JC009983

Lee, H. J., and Chao, S. Y. (2003). A climatological description of circulation in and around the East China sea. Deep Sea Res. Part II Top. Stud. Oceanogr. 50, 1065-1084. doi: 10.1016/S0967-0645(03)00010-9

Lee, J. H., Moon, I. J., Moon, J. H., Kim, S. H., Jeong, Y. Y., and Koo, J. H. (2017). Impact of typhoons on the Changjiang plume extension in the Yellow and East China seas. J. Geophy. Res. Oceans 122, 4962-4973. doi: 10.1002/2017JC012754

Li, G. X., Qiao, L. L., Dong, P., Ma, Y. Y., Xu, J. S., Liu, S. D., et al. (2016). Hydrodynamic condition and suspended sediment diffusion in the Yellow sea and East China sea. J. Geophys. Res. Oceans 121, 6204-6222. doi: 10.1002/2015JC011442

Li, H. M., Tang, H. J., Shi, X. Y., Zhang, C. S., and Wang, X. L. (2014a). Increased nutrient loads from the Changjiang (Yangtze) river have led to increased harmful algal blooms. Harmful Algae 39, 92-101. doi: 10.1016/j.hal.2014.07.002

Li, L., Zhu, J. R., and Wu, H. (2012). Impacts of wind stress on saltwater intrusion in the Yangtze estuary. Sci. China Earth Sci. 55, 1178-1192. doi: 10.1007/s11430-011-4311-1

Li, L., Zhu, J. R., Wu, H., and Guo, Z. G. (2014). Lateral saltwater intrusion in the north channel of the Changjiang estuary. Estuar. Coasts 37, 36-55. doi: $10.1007 /$ s12237-013-9669-1

Li, L., Zhu, J. R., Wu, H., and Wang, B. (2010). A numerical study on water diversion ratio of the Changiang (Yangtze) estuary in dry season. Chin. J. Oceanol. Limnol. 28, 700-712. doi: 10.1007/s00343-010-9114-2

Li, L. J., Zhu, J. R., Chant, R. J., Wang, C. N., and Pareja-Roman, L. F. (2020). Effect of dikes on saltwater intrusion under various wind conditions in the Changiiang estuary. J. Geophys. Res. Oceans 125:e2019JC015685. doi: 10.1029/2019JC015685

Li, M., and Rong, Z. R. (2012). Effects of tides on freshwater and volume transports in the Changjiang river plume. J. Geophys. Res. Oceans 117:C06027. doi: 10.1029/2011JC007716

Li, P., Wang, S. J., Li, Y. G., and Qin, W. H. (2014b). Current conditions in summer in the Zhejiang offshore. J. Mar. Sic. 32, 16-25. doi: 10.3969/j.issn.1001-909X.2014.03.003

Li, Y. H., Qiao, L., Wang, A. J., Zhang, Y., Fang, J. Y., and Chen, J. (2013). Seasonal variation of water column structure and sediment transport in a mud depo-center off the Zhejiang-Fujian coast in China. Ocean Dyn. 63, 679-690. doi: 10.1007/s10236-013-0620-6

Li, Z. Y., and Huang, D. J. (2019). Sea surface height and current responses to synoptic winter wind in the Bohai, Yellow, and East China seas: two leading coastal trapped waves. J. Geophys. Res. Oceans 124, 2289-2312. doi: 10.1029/2018JC014120

Liang, X. S., Huang, M., Wu, H., and Wang, Y. (2018). “The Yellow sea surface cold patches in warm seasons," in Coastal Environment, Disaster, and Infrastructure - A Case Study of China's Coastline, eds X. S. Liang and Y. Zhang (London: IntechOpen). doi: 10.5772/intechopen.80732

Liblik, T., Wu, Y. J., Fan, D. D., and Shang, D. H. (2020). Wind-driven stratification patterns and dissolved oxygen depletion off the Changjiang (Yangtze) estuary. Biogeosciences 17, 2875-2895. doi: 10.5194/bg-17-2875-2020

Lie, H. J., and Cho, C. H. (1994). On the origin of the tsushima warm current. J. Geophys. Res Oceans 99, 25081-25091. doi: 10.1029/94JC02425

Lie, H. J., and Cho, C. H. (2016). Seasonal circulation patterns of the Yellow and East China seas derived from satellite-tracked drifter trajectories and hydrographic observations. Prog. Oceanogr. 146, 121-141. doi: 10.1016/j.pocean.2016.06.004

Lie, H. J., Cho, C. H., Lee, J. H., and Lee, S. (2003). Structure and eastward extension of the Changjiang River plume in the East China sea. J. Geophys. Res. Oceans 108:3077. doi: 10.1029/2001JC001194

Lin, X. P., and Yang, J. Y. (2011). An asymmetric upwind flow, Yellow Sea Warm Current: 2. Arrested topographic waves in response to the northwesterly wind. J. Geophys. Res. Oceans 116:C04027. doi: 10.1029/2010JC006514

Lin, X. P., Yang, J. Y., Guo, J. S., Zhang, Z. X., Yin, Y. Q., Song, X. Z., et al. (2011). An asymmetric upwind flow, Yellow sea warm current: 1 . New observations in the western Yellow sea. J. Geophys. Res. Oceans 116:C04026. doi: 10.1029/2010JC0 06513

Liu, X., Beusen, A. H. W., Beek, L. P. H. V., Mogollón, J. M., Ran, X., and Bouwman, A. F. (2018). Exploring spatiotemporal changes of the Yangtze river (Changjiang) nitrogen and phosphorus sources, retention and export to the East China sea and Yellow sea. Water Res. 142, 246-255. doi: 10.1016/j.watres.2018.06.006

Liu, X. B., and Su, J. L. (1991). Numerical study of coastal upwelling and jet along Zhejiang. Acta Oceanol. Sin. 13, 305-314.

Liu, Z. Q., and Gan, J. P. (2014). Modeling study of variable upwelling circulation in the east China sea: response to a coastal promontory. J. Phys. Oceanogr. 44, 1078-1094. doi: 10.1175/JPO-D-13-0170.1

Liu, Z. Q., and Gan, J. P. (2015). Upwelling induced by the frictional stress curl and vertical squeezing of the vortex tube over a submerged valley in the East China sea. J. Geophys. Res. Oceans 120, 2571-2587. doi: 10.1002/2015JC010715

Liu, Z. Q., and Gan, J. P. (2016). Open boundary conditions for tidally and subtidally forced circulation in a limited-area coastal model using the regional ocean modeling system (ROMS). J. Geophys. Res. Oceans 121, 6184-6203. doi: 10.1002/2016JC011975

Liu, Z. Q., Gan, J. P., Hu, J. Y., Wu, H., Cai, Z. Y., and Deng, Y. F. (2021). Progress of studies on circulation dynamics in the East China sea: the kuroshio exchanges with the shelf currents. Front. Mar. Sci. doi: $10.3389 /$ fmars.2021.620910

Lu, H. F., Gu, F. F., Qi, D. M., Chen, X. E., and Wang, Y. Y. (2019). Investigating near-bottom hydrodynamic processes in the yangtze river estuary using in situ measurements. J. Coast. Res. 35, 805-813. doi: 10.2112/JCOASTRES-D-18-00131.1

Lu, L. F., and Shi, J. Z. (2007). The dispersal processes within the tide-modulated Changjiang river plume, China. Int. J. Num. Methods Fluids 55, 1143-1155. doi: $10.1002 /$ fld. 1520

Lu, S., Tong, C. F., Lee, D. Y., Zheng, J. H., Shen, J., Zhang, W., et al. (2015). Propagation of tidal waves up in Yangtze estuary during the dry season. $J$. Geophys. Res. Oceans 120, 6445-6473. doi: 10.1002/2014J. C.010414

Lü, X., Qiao, F., Xia, C., Wang, G., and Yuan, Y. (2010). Upwelling and surface cold patches in the Yellow sea in summer: effects of tidal mixing on the vertical circulation. Cont. Shelf Res. 30, 620-632. doi: 10.1016/j.csr.2009.09.002

Lü, X. G., Qiao, F., Xia, C., Zhu, J., and Yuan, Y. (2006). Upwelling off Yangtze river estuary in summer. J. Geophys. Res. 111:C11S08. doi: 10.1029/2005JC003250

Luan, H. L., Ding, P. X., Wang, Z. B., Ge, J. Z., and Yang, S. L. (2016), Decadal morphological evolution of the Yangtze estuary in response to river input changes and estuarine engineering projects. Geomorphology 265, 12-23. doi: 10.1016/j.geomorph.2016.04.022

Lui, H.-K., Chen, C.-T. A., Lee, J., Bai, Y., and He, X. (2014). Looming hypoxia on outer shelves caused by reduced ventilation in the open oceans: case study of the East China sea. Estuar. Coast. Shelf Sic. 151, 355-360. doi: $10.1016 /$ j.ecss. 2014.08 .010

Lui, H.-K., Chen, C.-T. A., Lee, J., Wang, S.-L., Gong, G.-C., Bai, Y., et al. (2015). Acidifying intermediate water accelerates the acidification of seawater on shelves: an example of the East China sea. Cont. Shelf Res. 111, 223-233. doi: 10.1016/j.csr.2015.08.014

Luo, X., Wei, H., Fan, R., Liu, Z., Zhao, L., and Lu, Y. (2018). On influencing factors of hypoxia in waters adjacent to the Changjiang estuary. Cont. Shelf Res. 152, 1-13. doi: $10.1016 /$ j.csr.2017.10.004

Lyu, H. H., and Zhu, J. R. (2018). Impact of the bottom drag coefficient on saltwater intrusion in the extremely shallow estuary. J. Hydrol. 557, 838-850. doi: 10.1016/j.jhydrol.2018.01.010

Ma, G. F., Shi, F. Y., Liu, S. G., and Qi, D. M. (2011). Hydrodynamic modeling of Changjiang estuary: model skill assessment and large-scale structure impacts. Appl. Ocean Res. 33, 69-78. doi: 10.1016/j.apor.2010.10.004

Matsuno, T. (2020). "The changing east China sea-a physical view," in Changing Asia-Pacific Marginal Seas, eds C. T.A. Chen and X. Guo. (Singapore: Springer Singapore), 139-153.

Mei, X. F., Dai, Z. J., Van Gelder, P. H.,a,J. M., and Gao, J.J. (2015). Linking three gorges dam and downstream hydrological regimes along the Yangtze river, China. Earth and Space Sci. 2, 94-106. doi: 10.1002/2014E A000052

Meng, Q. J., Li, P. L., Zhai, F. G., and Gu, Y. Z. (2020). The vertical mixing induced by winds and tides over the Yellow sea in summer: a numerical study in 2012. Ocean Dyn. 70, 847-861. doi: 10.1007/s10236-020-01368-2

Moon, J. H., Hirose, N., Pang, I. C., and Hyun, K. H. (2012). Modeling offshore freshwater dispersal from the Changjiang river and controlling factors during summer. Terr. Atmos. Ocean. Sci. 23, 247-260. doi: 10.3319/TAO.2012.01.10.01(Oc) 
Moon, J. H., Hirose, N., Yoon, J. H., and Pang, I. C. (2010). Offshore detachment process of the low-salinity water around Changjiang bank in the East China sea. J. Phys. Oceanogr. 40, 1035-1053. doi: 10.1175/2010JPO4167.1

Moon, J. H., Kim, T., Son, Y. B., Hong, J. S., Lee, J. H., Chang, P. H., et al. (2019). Contribution of low-salinity water to sea surface warming of the East China sea in the summer of 2016. Prog. Oceanogr. 175, 68-80. doi: 10.1016/j.pocean.2019.03.012

Ni, X., Huang, D., Zeng, D., Zhang, T., Li, H., and Chen, J. (2016). The impact of wind mixing on the variation of bottom dissolved oxygen off the Changjiang estuary during summer. J. Mar. Syst. 154, 122-130. doi: 10.1016/j.jmarsys.2014.11.010

Oh, K. H., Lee, J. H., Lee, S., and Pang, I. C. (2014). Intrusion of lowsalinity water into the Yellow sea interior in 2012. Ocean Sci. J. 49, 343-356. doi: 10.1007/s12601-014-0032-7

$\mathrm{Pu}, \mathrm{X}$., Shi, J. Z., and Hu, G. (2017). The effect of stratification on the vertical structure of the tidal ellipse in the Changjiang river estuary, China. J. Hydro Environ. Res. 15, 75-94. doi: 10.1016/j.jher.2017.03.004

$\mathrm{Pu}, \mathrm{X}$., Shi, J. Z., and Hu, G. D. (2016). Analyses of intermittent mixing and stratification within the north passage of the Changjiang (Yangtze) river estuary, China: a three-dimensional model study. J. Mar. Syst. 158, 140-164. doi: 10.1016/j.jmarsys.2016.02.004

$\mathrm{Pu}, \mathrm{X}$., Shi, J. Z., Hu, G. D., and Xiong, L. B. (2015). Circulation and mixing along the north passage in the Changjiang river estuary, China. J. Mar. Syst. 148, 213-235. doi: 10.1016/j.jmarsys.2015.03.009

Qian, W., Dai, M. H., Xu, M., Kao, S. J., Du, C. J., Liu, J. W., et al. (2017). Non-local drivers of the summer hypoxia in the East China sea off the Changjiang estuary. Estuar. Coast. Shelf Sci. 198, 393-399. doi: 10.1016/j.ecss.2016.08.032

Qiao, F. L., Wang, G. S., Lu, X. G., and Dai, D. J. (2011). Drift characteristics of green macroalgae in the Yellow sea in 2008 and 2010. Chin. Sci. Bull. 56, 2236-2242. doi: 10.1007/s11434-011-4551-7

Qiao, F. L., Yang, Y. Z., Lv, X. G., Xia, C. S., Chen, X. Y., Wang, B. D., et al. (2006). Coastal upwelling in the East China sea in winter. J. Geophys. Res. Oceans 111:C11S06. doi: 10.1029/2005JC003264

Qiu, C., Zhu, J., and Gu, Y. (2012). Impact of seasonal tide variation on saltwater intrusion in the Changjiang river estuary. Chin. J. Oceanol. Limnol. 30, 342-351. doi: $10.1007 / \mathrm{s} 00343-012-1115-\mathrm{x}$

Rabouille, C., Conley, D. J., Dai, M. H., Cai, W. J., Chen, C. T. A., Lansard, B., et al. (2008). Comparison of hypoxia among four river-dominated ocean margins: the Changjiang (Yangtze), Mississippi, Pearl, and Rhone rivers. Cont. Shelf Res. 28, 1527-1537. doi: 10.1016/j.csr.2008.01.020

Rong, Z., and Li, M. (2012). Tidal effects on the bulge region of Changjiang river plume. Estuar. Coast. Shelf Sic. 97, 149-160. doi: 10.1016/j.ecss.2011.11.035

Senjyu, T., Enomoto, H., Matsuno, T., and Matsui, S. (2006). Interannual salinity variations in the tsushima strait and its relation to the Changjiang discharge. J. Oceanogr. 62, 681-692. doi: 10.1007/s10872-006-0086-y

Shan, F., Qiao, F. L., and Xia, C. S. (2009). A numerical study of summertime expansion pattern of Changjiang (Yangtze) river diluted water. Acta Oceanol. Sin. 28, 11-16.

Shen, J. Q., Qiu, Y., Guo, X. G., Pan, A. J., and Zhou, X. W. (2017). The spatio-temporal variation of wintertime subtidal currents in the western Taiwan strait. Acta Oceanol. Sin. 36, 4-13. doi: 10.1007/s13131-017$1120-1$

Shi, F., Luo, Y. Y., and Rong, Z. R. (2016). A numerical study of the summer circulation in the southwestern Yellow sea. Acta Oceanol. Sin. 35, 1-8. doi: 10.1007/s13131-016-0943-5

Shi, J. Z., and Lu, L. F. (2011). A short note on the dispersion, mixing, stratification and circulation within the plume of the partially-mixed Changjiang river estuary, China. J. Hydro Environ. Res. 5, 111-126. doi: 10.1016/j.jher.2010.06.002

Shi, W., and Wang, M. H. (2012). Satellite views of the Bohai sea, Yellow sea, and East China sea. Prog. Oceanogr. 104, 30-45. doi: 10.1016/j.pocean.2012.05.001

Song, X. Z., Huang, R. X., Wu, D. X., Qiao, F. L., and Wang, G. S. (2019). Geostrophic spirals generated by the horizontal diffusion of vortex stretching in the Yellow sea. Adv. Atmosph. Sci. 36, 219-230. doi: 10.1007/s00376-0188091-9

Sun, J., Yang, D., Yin, B., Chen, H., and Feng, X. (2018). Onshore warm tongue and offshore cold tongue in the western Yellow sea in winter: the evidence. $J$. Oceanol. Limnol. 36, 1475-1483. doi: 10.1007/s00343-018-7021-0
Tong, Y., Bu, X., Chen, J., Zhou, F., Chen, L., Liu, M., et al. (2017). Estimation of nutrient discharge from the Yangtze river to the East China sea and the identification of nutrient sources. J. Hazard. Mater. 321, 728-736. doi: 10.1016/j.jhazmat.2016.09.011

Wan, Y., Gu, F., Wu, H., and Roelvink, D. (2014). Hydrodynamic evolutions at the Yangtze estuary from 1998 to 2009. Appl. Ocean Res. 47, 291-302. doi: 10.1016/j.apor.2014.06.009

Wan, Y., and Zhao, D. (2017). Observation of saltwater intrusion and ETM dynamics in a stably stratified estuary: the Yangtze estuary, China. Environ. Monit. Assess. 189:89. doi: 10.1007/s10661-017-5797-6

Wang, B., Chen, J., Jin, H., Li, H., Huang, D., and Cai, W.-J. (2017a). Diatom bloom-derived bottom water hypoxia off the Changjiang estuary, with and without typhoon influence. Limnol. Oceanogr. 62, 1552-1569. doi: 10.1002/lno.10517

Wang, B., Hirose, N., Moon, J. H., and Yuan, D. L. (2013a). Difference between the Lagrangian trajectories and eulerian residual velocity fields in the southwestern Yellow sea. Ocean Dynam. 63, 565-576. doi: 10.1007/s10236-013-0607-3

Wang, B., Hirose, N., Yuan, D. L., Moon, J. H., and Pan, X. S. (2017b). Effects of tides on the cross-isobath movement of the low-salinity plume in the western Yellow and East China seas in winter. Cont. Shelf Res. 143, 228-239. doi: 10.1016/j.csr.2016.06.011

Wang, B., Li, Y., and Yuan, D. L. (2013b). Effects of topography on the sub-tidal circulation in the southwestern Huanghai sea (Yellow sea) in summer. Acta Oceanol. Sin. 32, 1-9. doi: 10.1007/s13131-013-0282-8

Wang, B., Wei, Q., Chen, J., and Xie, L. (2012). Annual cycle of hypoxia off the Changjiang (Yangtze river) estuary. Mar. Environ. Res. 77, 1-5. doi: 10.1016/j.marenvres.2011.12.007

Wang, B., Xin, M., Wei, Q., and Xie, L. (2018). A historical overview of coastal eutrophication in the China seas. Mar. Pollut. Bull. 136, 394-400. doi: 10.1016/j.marpolbul.2018.09.044

Wang, H., Dai, M., Liu, J., Kao, S. J., Zhang, C., Cai, W. J., et al. (2016). Eutrophication-driven hypoxia in the East China sea off the Changjiang estuary. Environ. Sci. Technol. 50, 2255-2263. doi: 10.1021/acs.est.5b06211

Wang, H., Sun, F. B., and Liu, W. B. (2020). Characteristics of streamflow in the main stream of Changjiang river and the impact of the three gorges dam. Catena 189:104498. doi: 10.1016/j.catena.2020.104498

Wang, J., Yan, W., Chen, N., Li, X., and Liu, L. (2015). Modeled long-term changes of DIN:DIP ratio in the Changjiang river in relation to Chl- $\alpha$ and DO concentrations in adjacent estuary. Estuar. Coast. Shelf Sic. 166, 153-160. doi: 10.1016/j.ecss.2014.11.028

Wang, J. F., Yu, F., Ren, Q., Si, G. C., and Wei, C. J. (2019a). The observed variations of the north intrusion of the bottom Taiwan warm current inshore branch and its response to wind. Reg. Stud. Mar. Sci. 30:17. doi: 10.1016/j.rsma.2019.100690

Wang, Y., Shen, J., He, Q., Zhu, L., and Zhang, D. (2015). Seasonal variations of transport time of freshwater exchanges between Changjiang estuary and its adjacent regions. Estuar. Coast. Shelf Sci. 157, 109-119. doi: $10.1016 /$ j.ecss.2015.03.008

Wang, Y., Shen, J. A., and He, Q. (2010). A numerical model study of the transport timescale and change of estuarine circulation due to waterway constructions in the Changjiang estuary, China. J. Mar. Syst. 82, 154-170. doi: 10.1016/j.jmarsys.2010.04.012

Wang, Y., Wu, H., Lin, J., Zhu, J., Zhang, W., and Li, C. (2019c). Phytoplankton blooms off a high turbidity estuary: a case study in the Changjiang river estuary. J. Geophys. Res. Oceans 124, 8036-8059. doi: 10.1029/2019JC015343

Wang, Y. H., Wu, H., Gao, L., Shen, F., and Liang, X. S. (2019b). Spatial distribution and physical controls of the spring algal blooming off the Changjiang river estuary. Estuar. Coasts 42, 1066-1083. doi: 10.1007/s12237-019-00545-x

Wei, H., He, Y. C., Li, Q. J., Liu, Z. Y., and Wang, H. T. (2007). Summer hypoxia adjacent to the Changjiang estuary. J. Mar. Syst. 67, 292-303. doi: 10.1016/j.jmarsys.2006.04.014

Wei, Q., Wang, B., Yu, Z., Chen, J., and Xue, L. (2017b). Mechanisms leading to the frequent occurrences of hypoxia and a preliminary analysis of the associated acidification off the Changjiang estuary in summer. Sci. China Earth Sci. 60, 360-381. doi: 10.1007/s11430-015-5542-8

Wei, Q., Wang, B., Zhang, X., Ran, X., Fu, M., Sun, X., et al. (2020). Contribution of the offshore detached Changjiang (Yangtze river) diluted water to the formation of hypoxia in summer. Sci. Total Environ. doi: 10.1016/j.scitotenv.2020.142838 
Wei, Q. S., Yu, Z. G., Wang, B. D., Fu, M. Z., Xia, C. S., Liu, L., et al. (2016). Coupling of the spatial-temporal distributions of nutrients and physical conditions in the southern Yellow sea. J. Mar. Syst. 156, 30-45. doi: 10.1016/j.jmarsys.2015.12.001

Wei, Q. S., Yu, Z. G., Wang, B. D., Wu, H., Sun, J. C., Zhang, X. L., et al. (2017a). Offshore detachment of the Changiiang River plume and its ecological impacts in summer. J. Oceanogr. 73, 277-294. doi: 10.1007/s10872-0160402-0

Wei, Q. S., Yu, Z. G., Xia, C. S., Zang, J. Y., and Zhang, X. L. (2011). A preliminary analysis on the dynamic characteristics of the hypoxic zone adjacent to the Changiiang estuary in summer. Acta Oceanol. Sin. 33, 100-109.

$\mathrm{Wu}, \mathrm{H}$. (2015). Cross-shelf penetrating fronts: a response of buoyant coastal water to ambient pycnocline undulation. J. Geophys. Res. Oceans 120, 5101-5119. doi: 10.1002/2014JC010686

Wu, H., Deng, B., Yuan, R., Hu, J., Gu, J. H., Shen, F., Zhu, J. R., and Zhang, J. (2013). Detiding measurement on transport of the changjiang-derived buoyant coastal current. J. Phys. Oceanogr. 43. 2388-2399. doi: 10.1175/Jpo-D-12-0158.1

$\mathrm{Wu}, \mathrm{H} ., \mathrm{Gu}, \mathrm{J} . \mathrm{H}$., and $\mathrm{Zhu}, \mathrm{P}$. (2018a). Winter counter-wind transport in the inner southwestern yellow sea. J. Geophys. Res. Oceans 123, 411-436. doi: 10.1002/2017JC013403

Wu, H., Shen, J., Zhu, J. R., Zhang, J., and Li, L. (2014). Characteristics of the Changjiang plume and its extension along the Jiangsu Coast. Conti. Shelf Res. 76, 108-123. doi: 10.1016/j.csr.2014.01.007

Wu, H., Wu, T., Shen, J., and Zhu, J. (2018b). "Dynamics of the Changjiang river plume," in Coastal Environment, Disaster, and Infrastructure - A Case Study of China's Coastline, eds X. S. Liang and Y. Zhang (London: IntechOpen). doi: $10.5772 /$ intechopen. 80734

Wu, H., Wu, T. N., and Bai, M. (2018c). Mega estuarine constructions modulate the Changjiang river plume extension in adjacent seas. Estuar. Coasts 41, 1234-1252. doi: 10.1007/s12237-017-0357-4

$\mathrm{Wu}, \mathrm{H}$., and Zhu, J. R. (2010). Advection scheme with 3rd high-order spatial interpolation at the middle temporal level and its application to saltwater intrusion in the Changjiang estuary. Ocean Model. 33, 33-51. doi: 10.1016/j.ocemod.2009.12.001

Wu, H., Zhu, J. R., Chen, B. R., and Chen, Y. Z. (2006). Quantitative relationship of runoff and tide to saltwater spilling over from the north branch in the Changjiang estuary: a numerical study. Estuar. Coast. Shelf Sci. 69, 125-132. doi: 10.1016/j.ecss.2006.04.009

Wu, H., Zhu, J. R., and Choi, B. H. (2010). Links between saltwater intrusion and subtidal circulation in the Changjiang estuary: a model-guided study. Conti. Shelf Res. 30, 1891-1905. doi: 10.1016/j.csr.2010.09.001

Wu, H., Zhu, J. R., Shen, J., and Wang, H. (2011). Tidal modulation on the Changjiang river plume in summer. J. Geophys. Res. Oceans 116:C08017. doi: 10.1029/2011JC007209

Wu, L. G., Wang, B., and Geng, S. Q. (2005). Growing typhoon influence on east Asia. Geophys. Res. Lett. 32:L18703. doi: 10.1029/2005GL022937

$\mathrm{Wu}, \mathrm{T}$. N., and Wu, H. (2018). Tidal mixing sustains a bottom-trapped river plume and buoyant coastal current on an energetic continental shelf. J. Geophys. Res. Oceans 123, 8026-8051. doi: 10.1029/2018JC014105

Wu, Y., Fan, D., Wang, D., and Yin, P. (2020). Increasing hypoxia in the Changjiang estuary during the last three decades deciphered from sedimentary redox-sensitive elements. Mar. Geol. 419:106044. doi: 10.1016/j.margeo.2019.106044

Xia, C. S., Qiao, F. L., Yang, Y. Z., Ma, J., and Yuan, Y. L. (2006). Threedimensional structure of the summertime circulation in the Yellow sea from a wave-tide-circulation coupled model. J. Geophys. Res. Oceans 111:C11S03. doi: 10.1029/2005JC003218

Xu, Z., Ma, J., Wang, H., Hu, Y. J., Yang, G. Y., and Deng, W. (2018). River discharge and saltwater intrusion level study of Yangtze river estuary, China. Water 10:683. doi: 10.3390/w10060683

Xu, Z. L., Shen, X. M., and Gao, Q. (2015). "Marine biology of the Changjiang (Yangtze river) estuary and adjacent East China sea shelf," in Ecological Continuum from the Changjiang (Yangtze River) Watersheds to the East China Sea Continental Margin, ed J. Zhang (Cham: Springer International Publishing), 161-180.

Xuan, J. L., Huang, D. J., Pohlmann, T., Su, J., Mayer, B., Ding, R. B., et al. (2016a). Synoptic fluctuation of the taiwan warm current in winter on the East China sea shelf. Ocean Sci. 13, 105-122. doi: 10.5194/os-13-105-2017
Xuan, J. L., Huang, D. J., Zhou, F., Zhu, X. H., and Fan, X. P. (2012). The role of wind on the detachment of low salinity water in the Changjiang estuary in summer. J. Geophys. Res. Oceans 117:C10004. doi: 10.1029/2012JC008121

Xuan, J. L., Yang, Z. Q., Huang, D. J., Wang, T. P., and Zhou, F. (2016b). Tidal residual current and its role in the mean flow on the Changiiang bank. J. Mar. Syst. 154, 66-81. doi: 10.1016/j.jmarsys.2015.04.005

Xue, P. F., Chen, C. S., Ding, P. X., Beardsley, R. C., Lin, H. C., Ge, J. Z., et al. (2009). Saltwater intrusion into the Changjiang river: a model-guided mechanism study. J. Geophys. Res. Oceans 114:C02006. doi: 10.1029/2008JC004831

Yan, X. H., Jo, Y. H., Jiang, L., Wan, Z. W., Liu, W. T., Li, Y., et al. (2008). Impact of the three gorges dam water storage on the Yangtze river outflow into the East China sea. Geophys. Res. Lett. 35:L05610. doi: 10.1029/2007GL032908

Yang, D., Yin, B., Chai, F., Feng, X., Xue, H., Gao, G., et al. (2018). The onshore intrusion of Kuroshio subsurface water from February to July and a mechanism for the intrusion variation. Prog. Oceanog. 167, 97-115. doi: 10.1016/j.pocean.2018.08.004

Yang, D. Z., Yin, B. S., Sun, J. C., and Zhang, Y. (2013). Numerical study on the origins and the forcing mechanism of the phosphate in upwelling areas off the coast of Zhejiang province, China in summer. J. Mar. Syst. 123, 1-18. doi: 10.1016/j.jmarsys.2013.04.002

Yang, S. L., Xu, K. H., Milliman, J. D., Yang, H. F., and Wu, C. S. (2015). Decline of Yangtze River water and sediment discharge: impact from natural and anthropogenic changes. Sci. Rep. 5, 12581-12581. doi: 10.1038/srep12581

Yang, Z., Wang, H., Saito, Y., Milliman, J. D., Xu, K., Qiao, S., et al. (2006). Dam impacts on the Changjiang (Yangtze) river sediment discharge to the sea: the past 55 years and after the three gorges dam. Water Res. Res. 42:W04407. doi: 10.1029/2005WR003970

Yu, R.-C., Lü, S.-H., and Liang, Y.-B. (2018). "Harmful algal blooms in the coastal waters of China," in Global Ecology and Oceanography of Harmful Algal Blooms, eds P. M. Glibert, E. Berdalet, M. A. Burford, G. C. Pitcher \& M. Zhou (Cham: Springer International Publishing), 309-316.

Yu, X., Zhang, W., and Hoitink, A. J. F. (2020a). Impact of river discharge seasonality change on tidal duration asymmetry in the Yangtze river estuary. Sci. Rep. 10:6304. doi: 10.1038/s41598-020-62432-x

Yu, Y., Chen, S. H., Tseng, Y. H., Guo, X. Y., Shi, J., Liu, G. L., et al. (2020b). Importance of diurnal forcing on the summer salinity variability in the East China sea. J. Phys. Oceanogr. 50, 633-653. doi: 10.1175/JPO-D-19-0200.1

Yuan, D. L., Li, Y., He, L., Zhou, H., Li, R. X., Wang, F., et al. (2010). An observation of the three-dimensional structure of a cross-shelf penetrating front off the Changjiang mouth. Deep Sea Res. Part II Top. Stud. Oceanogr. 57, 1827-1834. doi: $10.1016 / j . d s r 2.2010 .04 .009$

Yuan, D. L., Li, Y., Wang, B., He, L., and Hirose, N. (2017). Coastal circulation in the southwestern Yellow sea in the summers of 2008 and 2009. Conti. Shelf Res. 143, 101-117. doi: 10.1016/j.csr.2017.01.022

Yuan, D. L., Qiao, F. L., and Su, J. (2005). Cross-shelf penetrating fronts off the southeast coast of China observed by MODIS. Geophys. Res. Lett. 32:L19603. doi: 10.1029/2005GL023815

Yuan, D. L., Zhu, J. R., Li, C. Y., and Hu, D. X. (2008). Cross-shelf circulation in the Yellow and East China seas indicated by MODIS satellite observations. J. Mar. Syst. 70, 134-149. doi: 10.1016/j.jmarsys.2007.04.002

Yuan, R., Wu, H., Zhu, J. R., and Li, L. (2016). The response time of the Changjiang plume to river discharge in summer. J. Mar. Syst. 154, 82-92. doi: 10.1016/j.jmarsys.2015.04.001

Zhai, W.-D., Zheng, L.-W., Li, C.-L., Xiong, T.-Q., and Wang, S.-Y. (2020). "Changing nutrients, dissolved oxygen and carbonate system in the bohai and yellow seas, China," in Changing Asia-Pacific Marginal Seas, eds C. T.A. Chen \& X. Guo (Singapore: Springer Singapore), 121-137.

Zhang, E. F., Gao, S., Savenije, H. H. G., Si, C. Y., and Cao, S. (2019a). Saline water intrusion in relation to strong winds during winter cold outbreaks: north branch of the Yangtze estuary. J. Hydrol. 574, 1099-1109. doi: 10.1016/j.jhydrol.2019.04.096

Zhang, F. Y., Lin, B. L., and Sun, J. (2019b). Current reversals in a large tidal river. Estuar. Coast. Shelf Sci. 223, 74-84. doi: 10.1016/j.ecss.2019.04.017

Zhang, F. Y., Sun, J., Lin, B. L., and Huang, G. X. (2018a). Seasonal hydrodynamic interactions between tidal waves and river flows in the Yangtze estuary. J. Mar. Syst. 186, 17-28. doi: 10.1016/j.jmarsys.2018.05.005

Zhang, W., Feng, H. C., Hoitink, A. J. F., Zhu, Y. L., Gong, F., and Zheng, J. H. (2017). Tidal impacts on the subtidal flow division at the main 
bifurcation in the Yangtze river delta. Estuar. Coast. Shelf Sci. 196, 301-314. doi: 10.1016/j.ecss.2017.07.008

Zhang, W., Wu, H., Hetland, R. D., and Zhu, Z. (2019c). On mechanisms controlling the seasonal hypoxia hot spots off the changiiang river estuary. $J$. Geophys. Res. Oceans 124, 8683-8700. doi: 10.1029/2019JC015322

Zhang, W. X., Wu, H., and Zhu, Z. Y. (2018b). Transient hypoxia extent off changjiang river estuary due to mobile changjiang river plume. J. Geophys. Res. Oceans 123, 9196-9211. doi: 10.1029/2018JC014596

Zhang, Y., Fan, D. D., and Qin, R. F. (2020). Estuary-shelf interactions off the Changjiang delta during a dry-wet seasonal transition. Mar. Geol. 426:13. doi: 10.1016/j.margeo.2020.106211

Zhang, Z. W., Wu, H., Yin, X. Q., and Qiao, F. L. (2018c). Dynamical response of Changjiang river plume to a severe typhoon with the surface wave-induced mixing. J. Geophys. Res. Oceans 123, 9369-9388. doi: 10.1029/2018JC014266

Zheng, J., Gao, S., Liu, G., Wang, H., and Zhu, X. (2016). Modeling the impact of river discharge and wind on the hypoxia off Yangtze estuary. Nat. Hazards Earth Syst. Sci. 16, 2559-2576. doi: 10.5194/nhess-16-2559-2016

Zhou, F., Chai, F., Huang, D. J., Xue, H. J., Chen, J. F., Xiu, P., et al. (2017). Investigation of hypoxia off the Changjiang estuary using a coupled model of ROMS-CoSiNE. Progr. Oceanogr. 159, 237-254. doi: 10.1016/j.pocean.2017.10.008

Zhu, J., Wu, H., and Li, L. (2015). "Hydrodynamics of the Changjiang estuary and adjacent seas," in Ecological Continuum from the Changjiang (Yangtze River) Watersheds to the East China Sea Continental Margin, ed. J. Zhang (Cham: Springer International Publishing), 19-45.

Zhu, J., Wu, H., Li, L., and Qiu, C. (2019). "Changjiang estuary," in Sediment Dynamics of Chinese Muddy Coasts and Estuaries, ed X. H. Wang (Academic Press), 51-75.

Zhu, J. R. (2003). Dynamic mechanism of the upwelling on the west side of the submerged river valley off the Changjiang mouth in summertime. Chin. Sci. Bull. 48, 2754-2758. doi: 10.1007/BF02901770

Zhu, J. R., Wu, H., Li, L., and Qiu, C. (2018a). "Saltwater Intrusion in the Changjiang Estuary," in Coastal Environment, Disaster, and Infrastructure, A Case Study of China's Coastline, eds X. San Liang and Y. Zhang (London: IntechOpen). doi: 10.5772/intechopen.80903

Zhu, J. R., Zhu, Z. Y., Lin, J., Wu, H., and Zhang, J. (2016a). Distribution of hypoxia and pycnocline off the Changjiang estuary, China. J. Mar. Syst. 154, 28-40. doi: 10.1016/j.jmarsys.2015.05.002
Zhu, L., He, Q., and Shen, J. (2018b). Modeling lateral circulation and its influence on the along-channel flow in a branched estuary. Ocean Dyn. 68, 177-191. doi: 10.1007/s10236-017-1114-8

Zhu, P., and $\mathrm{Wu}, \mathrm{H}$. (2018). Origins and transports of the low-salinity coastal water in the southwestern Yellow sea. Acta Oceanol. Sin. 37, 1-11. doi: 10.1007/s13131-018-1200-x

Zhu, S. X., He, Z. Y., Zhang, W. J., Xie, S. J., and Xu, Y. C. (2018c). Characteristics analysis for cold water patches off the Jiangsu coast in the last 35 a. Acta Oceanol. Sin. 37, 19-25. doi: 10.1007/s13131-0181293-2

Zhu, Z.-Y., Hu, J., Song, G.-D., Wu, Y., Zhang, J., and Liu, S.-M. (2016b). Phytoplankton-driven dark plankton respiration in the hypoxic zone off the Changjiang estuary, revealed by in vitro incubations. J. Mar. Syst. 154, 50-56. doi: 10.1016/j.jmarsys.2015.04.009

Zhu, Z.-Y., Wu, H., Liu, S.-M., Wu, Y., Huang, D.-J., Zhang, J., et al. (2017). Hypoxia off the Changjiang (Yangtze River) estuary and in the adjacent East China sea: quantitative approaches to estimating the tidal impact and nutrient regeneration. Mar. Pollut. Bull. 125, 103-114. doi: 10.1016/j.marpolbul.2017.07.029

Zhu, Z. Y., Zhang, J., Wu, Y., Zhang, Y. Y., Lin, J., and Liu, S. M. (2011). Hypoxia off the Changiiang (Yangtze river) estuary: oxygen depletion and organic matter decomposition. Mar. Chem. 125, 108-116. doi: 10.1016/j.marchem.2011. 03.005

Zuo, J. L., Song, J. M., Yuan, H. M., Li, X. G., Li, N., and Duan, L. Q. (2019). Impact of kuroshio on the dissolved oxygen in the East China sea region. J. Oceanol. Limnol. 37, 513-524. doi: 10.1007/s00343-019-7389-5

Conflict of Interest: The authors declare that the research was conducted in the absence of any commercial or financial relationships that could be construed as a potential conflict of interest.

Copyright (c) $2021 \mathrm{Liu}, \mathrm{Gan}, \mathrm{Wu}, \mathrm{Hu}$, Cai and Deng. This is an open-access article distributed under the terms of the Creative Commons Attribution License (CC BY). The use, distribution or reproduction in other forums is permitted, provided the original author(s) and the copyright owner(s) are credited and that the original publication in this journal is cited, in accordance with accepted academic practice. No use, distribution or reproduction is permitted which does not comply with these terms. 